\title{
A MODEL FOR A COUNTERCURRENT GAS-SOLID-SOLID TRICKLE FLOW REACTOR FOR EQUILIBRIUM REACTIONS. THE METHANOL SYNTHESIS
}

\author{
K. R. WESTERTERP ${ }^{\dagger}$ and M. KUCZYNSKI \\ Chemical Reaction Engineering Laboratories, Department of Chemical Engineering, Twente University \\ of Technology, P.O. Box 217, 7500 AE Enschede, The Netherlands
}

(Received 25 April 1986; accepted for publication 22 October 1986)

\begin{abstract}
A bstract-The theoretical background for a novel, countercurrent gas-solid-solid trickle flow reactor for equilibrium gas reactions is presented. A one-dimensional, steady-state reactor model is developed. The influence of the various process parameters on the reactor performance is discussed. The physical and chemical data used apply to the case of low-pressure methanol synthesis from $\mathrm{CO}$ and $\mathrm{H}_{2}$ with an amorphous silica-alumina as the product adsorbent. Complete reactant conversion is attainable in a single-pass operation, so that a recycle loop for the non-converted reactants is superfluous.

In the following article the installation and experiments for which this theory was developed will be described.
\end{abstract}

\section{INTRODUCTION}

\subsection{Problem area}

The economics of many industrial chemical processes are unfavourably influenced by the equilibrium limitations of the reaction(s) involved. This influence finds expression in high additional costs for the separation of non-converted reactants from the reactor outlet product and their recycling to the reactor inlet. In two of the most important industrial processes, the ammonia and the methanol syntheses, the desired product has to be separated from the reactor outlet mixture by condensation. The presence of the inert non-converted reactants reduces the heat-transfer coefficients in the condensers considerably, increasing thereby the required cooling area manifold. The noncondensed gases are recycled to the reactor. Due to this recycling the flows through the reactor are increased, increasing the pressure drop over the reactor and the condensers and so increasing the energy required for the compression of the recycle stream. As in the reactor the equilibrium is approached and consequently reaction rates are reduced, long reactor lengths are required, increasing again the pressure drop and the energy demand. Additional energy is required for cooling and heating over again the non-converted gaseous reactants in and after the condensing section. Not only is energy consumption increased due to the low conversions but also the investments in the plant. Therefore in order to reduce the production costs of, for example, two of the most important chemicals, $\mathrm{CH}_{3} \mathrm{OH}$ and $\mathrm{NH}_{3}$, there is a strong incentive to increase the conversion obtained in a reactor in which a reversible reaction is executed.

To achieve this goal we have started a research and development programme to increase the conversion of reversible reactions in packed tubular reactors. To this end, we extended the gas-solid trickle flow (GSTF)

tAuthor to whom correspondence should be addressed. principle, as has been developed and investigated by van Swaaij and co-workers, and developed it further into the gas-solid-solid trickle flow (GSSTF) system.

Our GSSTFR principle works as follows: in a conventional tubular reactor the gaseous reactant mixture flows upwards through the solid catalyst packing. Countercurrently a stream of a fine solid powder trickles downward over the catalyst; this powder selectively adsorbs the reaction product, e.g. $\mathrm{CH}_{3} \mathrm{OH}$ or $\mathrm{NH}_{3}$. As the product is removed from the gaseous reaction mixture, the reaction rates are not hampered by a reversed reaction and remain high. In this way, higher conversions and higher reaction rates (shorter reactors!) can be expected and, as a consequence, also smaller condenser trains and smaller recycle compressors. As an extreme, even almost complete conversion can be envisaged, so that the recycling is no longer necessary. This necessarily will result in considerable investment and operating costs (energy) savings (smaller reactors, smaller condensers and a smaller recycle compressor).

In this paper we will elaborate further on the GSSTF principle and develop a mathematical model to describe a GSSTF reactor for equilibrium reactions. In the following paper we will compare the model with experiments in a mini pilot plant. We will formulate a steady-state model for the countercurrent GSSTF reactor and discuss the influence of various process parameters on the behaviour of the reactor. We apply our model to the case of methanol synthesis from carbon monoxide and hydrogen over a copper catalyst with an amorphous silica-alumina powder as the methanol adsorbent, which has been studied experimentally.

\subsection{Literature survey}

The idea of contacting a gas and solid stream countercurrently in a packed column was patented in 1948 (Directie van de Staatsmijnen in Limburg, 1948). 
In 1965, a patent appeared (Compagnie de SaintGobain, 1965) in which a countercurrent gas-solid contactor was applied as a heat exchanger in a largescale plant. In the latter invention, a vertical column was used containing several packing layers supported by sieve plates. Further development led to a more sophisticated application of this "raining packed bed" column in a heat recovery system (Compagnie de Saint-Gobain, 1978). It lasted until around 1976 before the principles of the behaviour of a gas-solid trickle flow contactor were beginning to be investigated fundamentally: Roes and van Swaaij in their extensive hydrodynamic studies (Roes, 1978; Roes and van Swaaij, 1979a-e) reported on the countercurrent flow of air and a fluidizable cracking catalyst in a cylindrical column packed with Raschig and Pall rings as well as with cylindrical screens [see Fig. 1(a)]. A low pressure drop, high mass-transfer rates and low axial mixing have been observed. Moreover, high solid and gas load capacities made this system attractive for industrial adsorption applications.

Large et al. (1981) investigated the hydrodynamics of sand streaming countercurrently to air in a tubular column-called by them a "raining packed bed exchanger"-filled with dumped Pall rings. They observed two distinct operating regimes for their system: an unstable and a stable one and indicated that the latter was suitable for heat exchange purposes. Recently, Saatdjian and Large (1985) reported on their experiments with a countercurrent gas-solid heat exchanger filled with Pall rings. They found that the heat transfer was strongly enhanced due to the presence of the packing; they also proposed a theoretical model to describe the operation of this contactor.

To reduce the pressure drop and the static holdup of the powder in the column even more whilst maintaining the high contacting efficiency, the so-called "zig-zag contactor" was developed for gas-solid trickle flow operation (Noordergraaf et al., 1980a-c). As can be seen in Fig. 1(b), a stream of powder flows downwards over sloping baffles or through a zig-zag-shaped vertical channel. The gas is introduced at the bottom of the column and flows countercurrently to the solid. Noordergraaf et al. $(1980 \mathrm{a}-\mathrm{c})$ have demonstrated that the pressure drop and the axial mixing are indeed very low in this zig-zag contactor. Moreover, static holdup of powder is practically nil.

Despite the improved performance, the zig-zag contactor still has a low capacity. To increase the capacity and maintain the zig-zag principle, Verver and van Swaaij (Verver, 1984) developed the use of a column containing a regularly stacked packing for contacting a gas with a solid under trickle flow conditions [see Fig. 1(c)]. From their results it appears that such a GSTF column operates excellently as an adsorber and as a gas-solid heat exchanger as well. The same authors were also the first to study the feasibility of the GSTF system to a process involving a single chemical reaction. They reported a new sulphur removal process from gas streams based on direct dehydrogenation of $\mathrm{H}_{2} \mathrm{~S}$ to sulphur by oxygen or by $\mathrm{SO}_{2}$ with a zeolitic catalyst trickling through the gas stream (Verver, 1984). The elemental sulphur produced is adsorbed on the catalyst powder and leaves the reactor at the bottom. In this case, the solid plays the role of reaction catalyst and of product adsorbent simultaneously, while the packing is inert. In the temperature range of their study the reaction is practically irreversible.

To our knowledge, no research has been reported up to now on the applicability of the trickle flow principle to equilibrium reactions, nor to trickle flow systems where two different solids play a role in the process. In our case, one of the solid phases is the

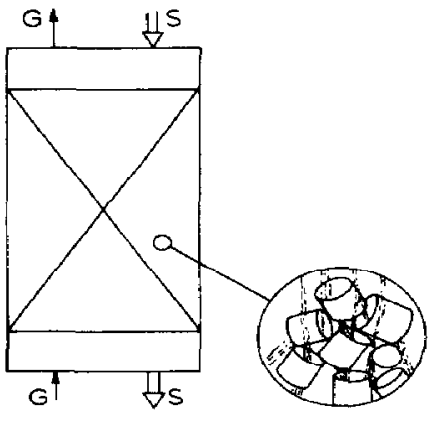

a)

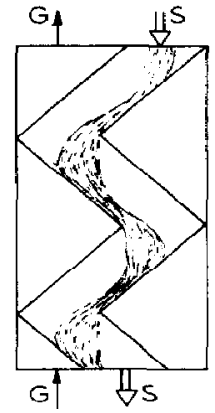

b)
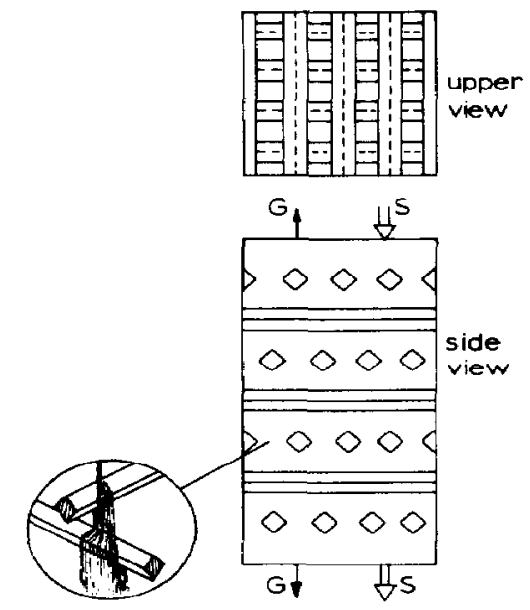

c)

Fig. 1. Countercurrent gas-solid tricklc flow contactors: (a) a column filled with a dumped packing; (b) a zigzag contactor, (c) a regularly packed or "multi zig-zag" column. 
catalyst and the other one is the trickling adsorbent.

\subsection{The GSSTF contactor as a reactor for equilibrium reactions}

In the process studied here (see Fig. 2), a mixture of gaseous reactants is introduced at the bottom of the packed column. The solid packing contains catalyst pellets. Another solid material, a selective product adsorbent, is fed at the top of the column and trickles down over the packing. This solids trickle flow over the dumped packing is illustrated in Fig. 3. The adsorbent powder is white and the catalyst particles are black. Also the Raschig rings can be distinguished. The hydrodynamic properties of this system are described elsewhere (Westerterp and Kuczynski, 1987).

The solids stream adsorbs the product formed immediately after it has been released from the catalyst surface. The reaction product therefore leaves the reactor in the adsorbed state at the lower end of the reactor. The unconverted reactants leave the reactor at the top, together with the non-adsorbed fraction of the product formed. As an extreme, a situation can be envisaged where a stoichiometric reactant mixture is completely converted and no gas at all leaves the reactor. No gas-solid separators, for example, cyclones, will be necessary if the linear gas velocity is sufficiently low. A strong influence of the solids stream on the thermal behaviour of the reactor can also be expected. For exothermic reactions, the released reaction and adsorption heats will be carried away both by the solids stream and by the gas stream in opposite

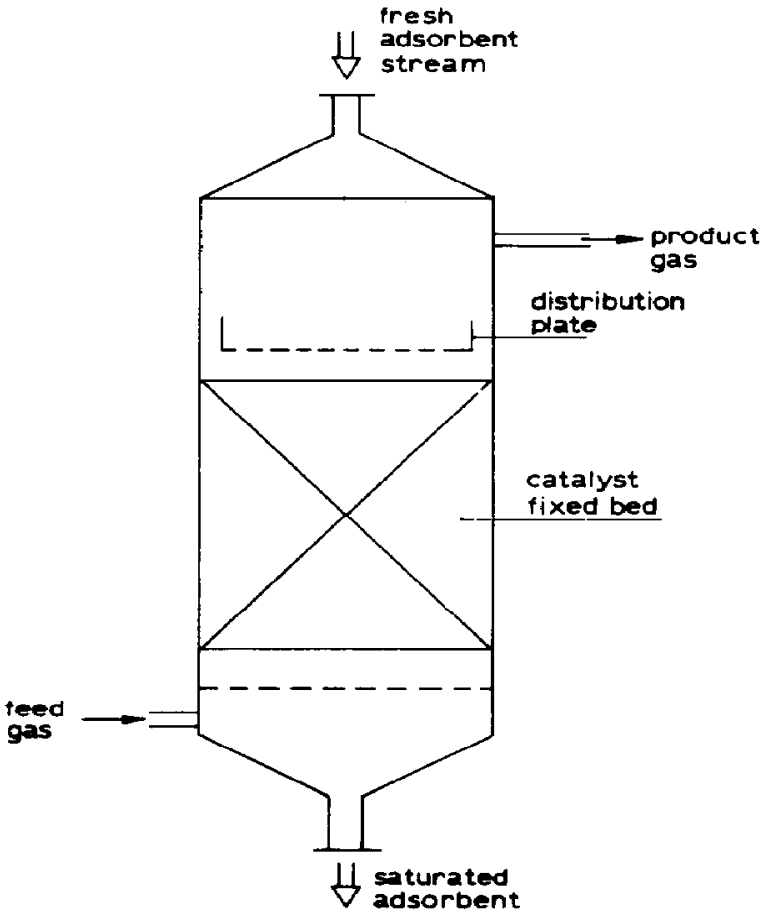

Fig. 2. The GSSTF contactor as a reactor for equilibrium reactions.

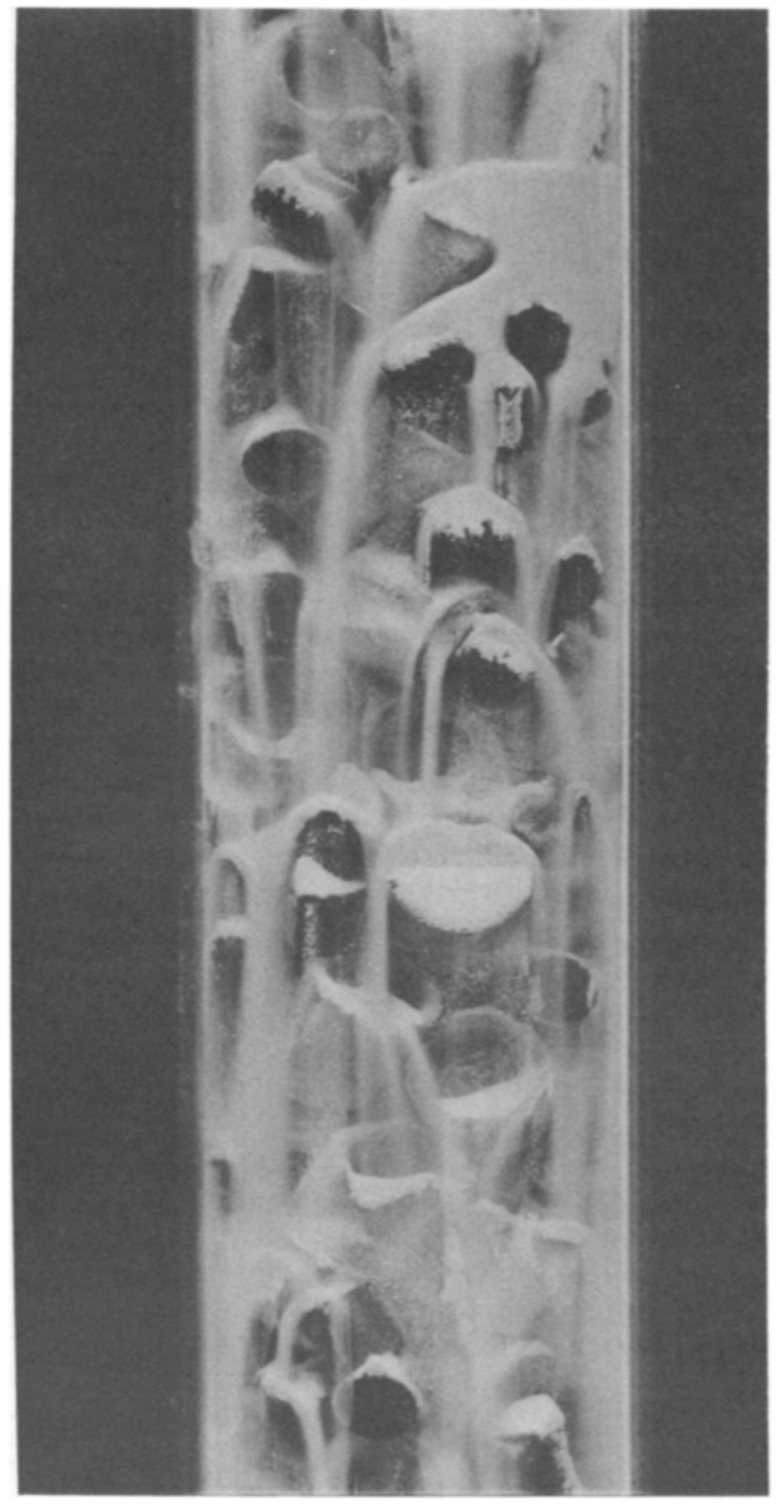

Fig. 3. Trickle flow of a silica-alumina powder (average particle diameter $\bar{d}_{\mathrm{p}} \approx 90 \times 10^{-6} \mathrm{~m}$ ) over a dumped packing consisting of $5 \times 5 \mathrm{~mm}$ catalyst pellets and $7 \times 7 \times 1 \mathrm{~mm}$ glass Raschig rings. The ratio of the pellets to the rings equals $2: 1$ by number and the tube diameter is $25 \times 10^{-3} \mathrm{~m}$.

directions. Simultaneously heat exchange between both phases occurs. So it can be expected that the axial temperature profile will be determined by the ratio of the heat capacities and of the flow rates of both streams, and, of course, by the extent to which the three phases possibly attain a thermal equilibrium when contacted in the column.

Our main objective is to describe the behaviour of the countercurrent GSSTF reactor for the case of exothermic equilibrium reactions catalysed by a solid. The ammonia and methanol syntheses, both processes of great industrial importance, are examples of such reactions. 


\section{MATHEMATICAL DESCRIPTION OF THE REACTING SYSTEM}

\subsection{Assumptions}

We consider a process involving a heterogeneously catalysed exothermic equilibrium reaction of gaseous reactants to a gaseous product:

$$
v_{A} A+v_{B} B=v_{P} P
$$

and an equilibrium product adsorption by a solid stream:

$$
\mathbf{P}+\mathbf{S}^{*} \rightleftarrows \mathrm{SP}^{*} .
$$

Here, $S^{*}$ stands for an active adsorption centre on the solid surface and $\mathrm{SP}^{*}$ represents an adsorbed product molecule. The position of the equilibrium of reaction (1) is affected strongly by the temperature and also by the total pressure, the effect of the latter being especially strong in cases where

$$
v_{\mathrm{A}}+v_{\mathrm{B}} \neq v_{\mathrm{P}} \text {. }
$$

The reaction is carried out in a reactor as sketched in Fig. 2. To derive a model we assume that the concentrations and the temperature are uniform over every cross-section of the reactor. Steady-state operation is considered. Furthermore, we assume that the adsorption of the reaction product is instantaneous so that adsorption equilibrium exists over the entire reactor length. At a given temperature, the product concentration in the solid phase can be described as a function of its partial pressure in the gas phase. For simplicity, we neglect the influence of the total pressure on the adsorption equilibrium. The pressure drop over the packed bed is also neglected.

We assume in the column plug flow both in the gas and in the solids streams. As was shown by Roes (1978) for the case where the extraction factor, defined as

$$
E_{\mathrm{F}}=\frac{u_{\mathrm{g}}}{m a u_{\mathrm{s}}}
$$

is equal to unity, the overall height $H_{\text {ov }}$ of a transfer unit is:

$$
H_{\mathrm{ov}}=H_{\mathrm{k}}+\frac{L}{P e_{\mathrm{g}}}+\frac{L}{P e_{\mathrm{s}}} \text {. }
$$

Here, $H_{k}$ is the height of a mass-transfer unit and $L / P e_{s}$ and $L / P e_{g}$ are the heights of axial mixing units for the solid and the gas phase, respectively. For a process involving a chemical reaction, we can write

$$
H_{\mathrm{ov}}=H_{\mathrm{k}}+\frac{L}{P e_{\mathrm{g}}}+\frac{L}{P e_{\mathrm{s}}}+\mathrm{HRU}
$$

where HRU is the height of a reaction unit. Our assumptions therefore imply that $\mathrm{HRU} \gg H_{\mathrm{k}}, L / P e_{\mathrm{g}}$ and $L / P e_{s}$. Equation (5) holds only for first-order kinetics; in that case,

$$
\text { HRU }=\frac{u_{\mathrm{g}}}{\varepsilon k \rho_{\mathrm{b}}} .
$$

So, in fact, we assume that the reactor capacity is determined exclusively by the chemical reaction rate.
Whether this assumption is realistic or not should be checked by comparing the reaction rate with the masstransfer rate of the reaction product from the bulk of the gas phase to the adsorbent surface. Generally, in a GSTF reactor the adsorbent particles have a small diameter, e.g. in the range from 50 to $100 \times 10^{-6} \mathrm{~m}$, and a relatively high linear velocity of the order of magnitude $0.2 \mathrm{~m} \mathrm{~s}^{-1}$, so the mass-transfer conditions are very good; thus in practice our assumptions are believed to be close to reality.

In the case of heterogeneously catalysed gas reactions, the heat of reaction is released at the catalyst surface. Similarly, the heat of adsorption is produced at the surface of the adsorbent. For simplicity and in order to be consistent with the previous assumptions, we assume that thermal equilibrium exists at each cross-section of the reactor. Moreover, heat transport by conduction in the axial direction is neglected. For computational simplicity, we assume that the adsorption equilibrium is described by a linear concentration dependence:

$$
C_{\mathrm{P}, \mathrm{s}}=m(T) C_{\mathrm{P}, \mathrm{g}}=m(T) \frac{p}{R_{\mathrm{g}} T} y_{\mathrm{p}} \quad(\mathrm{mol} \mathrm{P}) /\left(\mathrm{m}^{3} \text { solid }\right)
$$

where $m$ is the temperature-dependent distribution factor:

$$
m=m_{\infty} \exp \left(\frac{T_{\mathrm{m}}}{T}\right) \frac{(\mathrm{mol} \mathrm{P}) /\left(\mathrm{m}^{3} \text { solid }\right)}{\left.(\mathrm{mol} \mathrm{P}) / \mathrm{m}^{3} \text { gas }\right)} .
$$

Further, we assume that:

(a) the reactants are not adsorbed by the solid;

(b) there are no heat losses to the surroundings;

(c) the solids heat capacity is temperatureindependent; and

(d) the heat capacity of the gas is pressureindependent.

Moreover, in the case of strongly exothermic reactions cooling between the adiabatic reactor sections may become necessary to maintain the temperature within desired limits. In that case, we assume thermal and adsorption equilibrium at both ends of a cooling section.

\subsection{Basic balances}

For the differential reactor slice of Fig. 4 , the mass balances for the components $\mathrm{A}, \mathrm{B}$ and $\mathrm{P}$ are:

$$
\begin{aligned}
& \mathrm{d} \phi_{\mathrm{A}}=-\frac{v_{\mathrm{A}}}{v_{\mathrm{P}}} R_{\mathrm{P}} \rho_{\mathrm{b}} S \mathrm{~d} Z \\
& \mathrm{~d} \phi_{\mathrm{B}}=-\frac{v_{\mathrm{B}}}{v_{\mathrm{P}}} R_{\mathrm{P}} \rho_{\mathrm{b}} S \mathrm{~d} Z \\
& \mathrm{~d} \phi_{\mathrm{P}}=R_{\mathrm{P}} \rho_{\mathrm{b}} S \mathrm{~d} Z+\frac{\phi_{\mathrm{s}}}{\rho_{\mathrm{s}}} \mathrm{d} C_{\mathrm{P}, \mathrm{s}}
\end{aligned}
$$

with $\rho_{\mathrm{b}}$ the mass of the catalyst per unit of reactor volume $\left(\mathrm{kg} \mathrm{m}^{-3}\right)$ and $S$ the cross-section area of the reactor $\left(\mathrm{m}^{2}\right)$. In these equations, $\mathrm{d} \phi_{i}=\phi_{\mathrm{tot}} \mathrm{d} y_{i}$ $+y_{i} \mathrm{~d} \phi_{\mathrm{tot}}$. Further, $\phi_{i}$ is the flow of component $i$ in mol $s^{-1}, R_{p}$ is the production rate in mol $P$ produced 


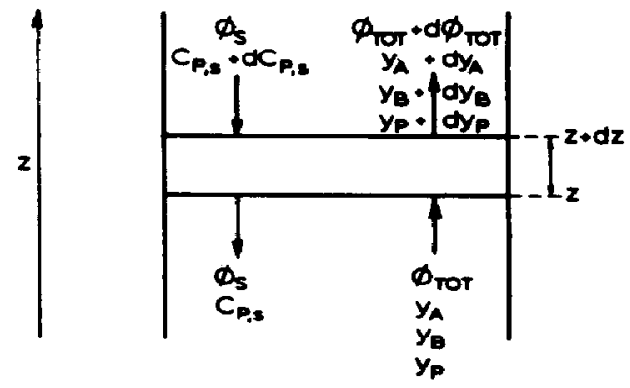

Fig. 4. A differential volume element of the GSSTFR.

( $\mathrm{kg}$ cat s) $)^{-1}$ and $C_{\mathrm{P}, \mathrm{s}}$ is the product concentration in the solid in mol $\mathrm{P} \mathrm{m}^{-3}$ solid. Using eqs (7) and (8), we can write for $\mathrm{d} C_{\mathrm{P}, \mathrm{s}}$ :

$$
\mathrm{d} C_{\mathrm{P}, \mathrm{s}}=\frac{p}{R_{\mathrm{g}} T}\left(y_{\mathrm{P}} \mathrm{d} m+m \mathrm{~d} y_{\mathrm{P}}-\frac{m y_{\mathrm{P}}}{T} \mathrm{~d} T\right)
$$

The heat balance for the reactor element of Fig. 4 is

$$
\begin{aligned}
\sum \phi_{i} c_{\mathrm{pg}} \mathrm{d} T= & R_{\mathrm{P}}\left(-\Delta H_{\mathrm{R}}\right) \rho_{\mathrm{b}} S \mathrm{~d} Z+\frac{\phi_{\mathrm{s}}}{\rho_{\mathrm{s}}} \Delta H_{\mathrm{A}} \mathrm{d} C_{\mathrm{P}, \mathrm{s}} \\
& +c_{\mathrm{ps}} \phi_{\mathrm{s},} \mathrm{d} T+c_{\mathrm{p}, \mathrm{P}}^{\mathrm{s}} \frac{\phi_{\mathrm{s}}}{\rho_{\mathrm{s}}} C_{\mathrm{P}, \mathrm{s}} \mathrm{d} T
\end{aligned}
$$

$\sum \phi_{i}$ represents the total molar flow of the gas and $c_{\mathrm{pg}}$ its molar heat capacity, the latter being a function of temperature and composition:

$$
c_{\mathrm{pg}}=y_{\mathrm{A}} c_{\mathrm{pg}, \mathrm{A}}(T)+y_{\mathrm{B}} c_{\mathrm{pg}, \mathrm{B}}(T)+y_{\mathrm{P}} c_{\mathrm{pg}, \mathrm{P}}(T)
$$

with $y_{A}+y_{B}+y_{P}=1$. $c_{p s}$ in eq. (13) is the solids heat capacity in $\mathrm{J} \mathrm{kg}^{-1} \mathrm{~K}^{-1}, e_{\mathrm{p}, \mathrm{P}}^{s}$ stands for the molar heat capacity of the product adsorbed and $\Delta H_{\mathrm{A}}$ and $\Delta H_{\mathrm{R}}$ are the heats of adsorption and of reaction per mol $\mathbf{P}$ adsorbed or produced, respectively.

For the cooling sections (see Fig. 5), the following balance equations hold:

and

$$
\begin{aligned}
\phi_{\mathrm{A} 1} & =\phi_{\mathrm{A} 2} \\
\phi_{\mathrm{B} 1} & =\phi_{\mathrm{B} 2}
\end{aligned}
$$

$$
\phi_{\mathrm{P} 2}-\phi_{\mathrm{P} 1}=\frac{\phi_{\mathrm{s}}}{\rho_{\mathrm{s}}}\left(C_{\mathrm{P}, \mathrm{s}, 2}-C_{\mathrm{P}, \mathrm{s}, 1}\right)
$$

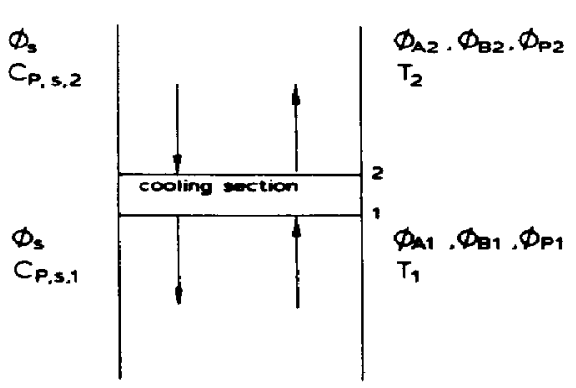

Fig. 5. A cooling section. where for the locations $j(1$ or 2$)$ :

$$
C_{\mathrm{P}, s, j}=m\left(T_{j}\right) \frac{p}{R_{\mathrm{g}} T_{j}} \frac{\phi_{\mathrm{P} j}}{\phi_{\mathrm{A}}+\phi_{\mathrm{B}}+\phi_{\mathrm{P} j}}
$$

\subsection{Boundary conditions}

At the reactor entrance and exit planes, product-free streams of the reactants and of the adsorbent, respectively, are supplied, while both streams leaving the reactor may contain reaction product. The correct choice of boundary conditions in multiphase, countercurrent processes often causes difficulties: it depends on the model used to describe the phenomena in the apparatus itself. In the case where a model based on discrete stages is used, usually the streams and concentrations in them are balanced according to the known transfer and conversion rates. In a differential model, the approach is in principle the same. In our case, however, we have assumed that the mass-transfer rates are infinitely high, so that adsorption equilibrium is attained everywhere. This leads to conceptual difficulties at the boundaries. On the interior of an inlet or outlet plane there is thermal and adsorption equilibrium between the gas and the solid streams; at the exterior side of these boundary planes there is no longer equilibrium between the incoming and outgoing streams. Consequently the mixing or demixing and the attainment of equilibrium occur instantaneously fast in the boundary plane itself. This is hard to visualize; nevertheless, boundary conditions based on this concept lead to good results in comparing the model and experiment, as will be shown later. The instantaneous saturation of the solids and gas feed streams assumed implies that there is a discontinuity in concentrations, flows and temperatures at both reactor ends. Our boundary conditions are illustrated by Fig. 6 .

The reactant gas entering the reactor at the lower reactor end $Z=0[$ Fig. 6 (b) ] does not contain reaction a.)

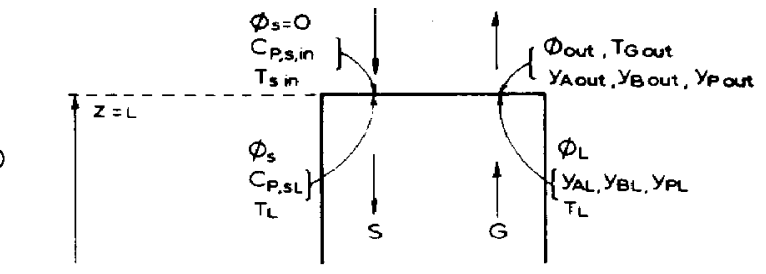

b.)

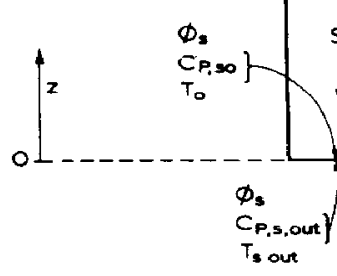

Fig. 6. The boundary conditions at the top and at the bottom of the GSSTFR. 
product, so that $y_{\mathrm{A}, \text { in }}+y_{\mathrm{B}, \text { in }}=1$; further, $T=T_{\mathrm{g}, \mathrm{in}}$. On entering the reactor, the gas is instantaneously saturated with the product so that adsorption equilibrium is attained. The inlet conditions for the lower end are defined by $\phi_{\text {in }}, T_{\text {gin }}$ and $y_{\mathrm{A}, \text { in }}$ outside the column and by $\phi_{\mathrm{Ao}}, \phi_{\mathrm{Bo}}, \phi_{\mathrm{Po}}$ and $T_{\mathrm{o}}$ as boundary values on the inside. Drawing up balances around the bottom plane leads to the following conditions at the interior side of the bottom plane for component $\mathrm{A}$ :

$$
\phi_{\mathrm{Ao}}=\phi_{\mathrm{in}} y_{\mathrm{A}, \mathrm{in}}
$$

for component $\mathbf{B}$ :

$$
\phi_{\mathrm{Bo}}=\phi_{\mathrm{in}}\left(1-y_{\mathrm{A}, \mathrm{in}}\right)
$$

for component $P$ :

with

$$
\phi_{\mathrm{Po}}=\frac{\phi_{\mathrm{s}}}{\rho_{\mathrm{s}}}\left(C_{\mathrm{P}, \mathrm{s}, \mathrm{o}}-C_{\mathrm{P}, \mathrm{s}, \mathrm{out}}\right)=\phi_{\mathrm{o}}-\phi_{\mathrm{in}}
$$

where

$$
C_{\mathrm{P}, \mathrm{s}, \mathrm{o}}=m\left(T_{\mathrm{o}}\right) \frac{p}{R_{\mathrm{g}} T_{\mathrm{o}}} *\left(1-y_{\mathrm{Ao}}-y_{\mathrm{Bo}}\right)
$$

$$
y_{i o}=\phi_{i o} /\left(\phi_{\mathrm{Ao}}+\phi_{\mathrm{Bo}}+\phi_{\mathrm{Po}}\right)=\phi_{i o} / \phi_{\mathrm{o}} \text {. }
$$

For the heat balance simplified by assuming the contribution of the methanol streams to be negligible in the enthalpy balance of the lower plane:

$$
\begin{aligned}
\phi_{\mathrm{s}} c_{\mathrm{ps}}\left(T_{\mathrm{o}}-T_{\mathrm{s}, \text { out }}\right)+\phi_{\text {in }} c_{\mathrm{pg}, \text { in }} & \left(T_{\mathrm{g}, \text { in }}-T_{\mathrm{o}}\right) \\
= & \left(\phi_{\mathrm{o}}-\phi_{\mathrm{in}}\right)\left(-\Delta H_{\mathrm{A}}\right) .
\end{aligned}
$$

The index "in" is ascribed to the parameter values outside and " $o$ " to those inside the reactor bottom plane. So there is a sudden change of conditions: the molar flow of the gas increases by $\phi_{\mathrm{Po}_{0}}$ on entering whereas the stream of the adsorbed product decreases by the same value while passing this boundary. At the upper reactor end $Z=L$, the fresh adsorbent entering the column is instantaneously saturated with the product so that adsorption equilibrium is reached. Here, the index "out" relates to the conditions outside, whereas the index " $L$ " is ascribed to the conditions inside the top plane of the reactor.

We now have for component $\mathrm{A}$ :

$$
\phi_{\mathrm{L}} y_{\mathrm{AL}}=\phi_{\text {out }} y_{\mathrm{A}, \mathrm{out}}
$$

for component $B$ :

$$
\phi_{\mathrm{L}} y_{\mathrm{BL}}=\phi_{\mathrm{out}} y_{\mathrm{B}, \mathrm{out}}
$$

for component P:

$$
\frac{\phi_{\mathrm{s}}}{\rho_{\mathrm{s}}} C_{\mathrm{P}, \mathrm{s}, \mathrm{L}}=\phi_{\mathrm{L}}\left(1-y_{\mathrm{AL}}-y_{\mathrm{BL}}\right)-\phi_{\mathrm{out}}\left(1-y_{\mathrm{A}, \text { out }}-y_{\mathrm{B}, \text { out }}\right)
$$

with

$$
C_{\mathrm{P}, s, \mathrm{~L}}=m\left(T_{\mathrm{L}}\right) \frac{p}{R_{\mathrm{g}} T_{\mathrm{L}}}\left(1-y_{\mathrm{AL}}-y_{\mathrm{BL}}\right)
$$

and for the heat balance:

$$
\begin{array}{r}
\phi_{\mathrm{s}} c_{\mathrm{ps}}\left(T_{\mathrm{L}}-T_{\mathrm{s}, \mathrm{in}}\right)-\left(-\Delta H_{\mathrm{A}}\right) \frac{\phi_{\mathrm{s}}}{\rho_{\mathrm{s}}} C_{\mathrm{P}, \mathrm{s}, \mathrm{L}}=\phi_{\mathrm{L}} c_{\mathrm{pg}, \mathrm{L}} T_{\mathrm{L}} \\
-\phi_{\text {out }} c_{\mathrm{pg}, \text { out }} T_{\text {g,out }}
\end{array}
$$

\subsection{Equations in dimensionless form}

To obtain the material balances in a dimensionless form, we introduce the mole fractions $y_{A}$ and $y_{B}$, the coordinate $z=Z / L$, the temperature $\theta=T / T_{\mathrm{R}}$ and the total gas flow $\psi \phi_{\text {in }}$, so that

$$
y_{\mathrm{A}}=\frac{\phi_{\mathrm{A}}}{\phi_{\text {in }} \psi}, \quad y_{\mathrm{B}}=\frac{\phi_{\mathrm{B}}}{\phi_{\text {in }} \psi} \quad \text { and } \quad \psi=\frac{\phi_{\mathrm{A}}+\phi_{\mathrm{B}}+\phi_{\mathrm{P}}}{\phi_{\text {in }}} \text {, }
$$

respectively. The differentials of the new variables $y_{A}$ and $y_{B}$ are

$$
\mathrm{d} y_{i}=\frac{\psi \mathrm{d} \phi_{i}-\phi_{i} \mathrm{~d} \psi}{\phi_{\text {in }} \psi^{2}}
$$

Equation (11) is replaced by the sum of eqns (9)-(11) to obtain the balance equation for the total gas flow. Further, we divide $R_{P}$ by $R_{P, R}$, in which $R_{P, R}$ is the production rate of $P$ in moles per kg catalyst and per second at the temperature $T_{\mathrm{R}}$, mole fractions $y_{\mathrm{A}}, y_{\mathrm{B}}$ and total pressure $p$, so that $R\left(y_{\mathrm{A}}, y_{\mathrm{B}}, p, \theta\right)=\boldsymbol{R}_{\mathrm{P}} / \boldsymbol{R}_{\mathrm{P} . \mathrm{R}}$, and we introduce $\mu=m / m_{R}$, where $m_{R}=m\left(T_{R}\right)$. We then obtain for component $A$ :

$$
\frac{\mathrm{d} y_{\mathrm{A}}}{\mathrm{d} z}=-\left(\frac{v_{\mathrm{A}}}{v_{\mathrm{P}}}\right) \frac{R D a}{\psi}-\frac{y_{\mathrm{A}}}{\psi} \frac{\mathrm{d} \psi}{\mathrm{d} z}
$$

for component $B$ :

$$
\frac{\mathrm{d} y_{\mathrm{B}}}{\mathrm{d} z}=-\left(\frac{v_{\mathrm{B}}}{v_{\mathrm{P}}}\right) \frac{R D a}{\psi}-\frac{y_{\mathrm{B}}}{\psi} \frac{\mathrm{d} \psi}{\mathrm{d} z}
$$

For the total gas flow:

$$
\begin{aligned}
\frac{\mathrm{d} \psi}{\mathrm{d} z}= & \left(\frac{v_{\mathrm{P}}-v_{\mathrm{A}}-v_{\mathrm{B}}}{v_{\mathrm{P}}}\right) R D a-\frac{E \mu y_{\mathrm{A}, \mathrm{in}}}{\theta} \\
& \times\left(1-y_{\mathrm{A}}-y_{\mathrm{B}}\right)\left(\frac{\frac{\mathrm{d} y_{\mathrm{A}}}{\mathrm{d} z}+\frac{\mathrm{d} y_{\mathrm{B}}}{\mathrm{d} z}}{1-y_{\mathrm{A}}-y_{\mathrm{B}}}\right. \\
& \left.+\frac{\frac{\mathrm{d} \theta}{\mathrm{d} z}}{\theta}\left(1+\frac{T_{\mathrm{m}}}{T_{\mathrm{R}} \theta}\right)\right)
\end{aligned}
$$

For the heat balance we divide both sides of eq. (13) by $T_{\mathrm{R}} \mathcal{c}_{\mathrm{pg}, \text { in }} \phi_{\text {in }}$, where

$$
c_{\mathrm{Pg}, \text { in }}=y_{\mathrm{A}, \mathrm{in}} c_{\mathrm{pg}, \mathrm{A}}\left(T_{\mathrm{R}}\right)+\left(1-y_{\mathrm{A}, \mathrm{in}}\right) c_{\mathrm{pg}, \mathrm{B}}\left(T_{\mathrm{R}}\right) .
$$

Moreover,

We then obtain

$$
\mu=\exp \left[\frac{T_{\mathrm{m}}}{T_{\mathrm{R}}}(1-\theta) / \theta\right] .
$$

$$
\begin{aligned}
& \frac{\mathrm{d} \theta}{\mathrm{d} z}\left(\psi \Gamma_{\mathrm{p}}-\beta-\frac{E \mu\left(1-y_{\mathrm{A}}-y_{\mathrm{B}}\right)}{\theta^{2}} \Delta \theta_{\mathrm{ad}, \mathrm{A}}\left(1+\frac{T_{\mathrm{m}}}{T_{\mathrm{R}} \theta}\right)\right. \\
& \left.-\frac{E \mu \delta}{\theta} y_{\mathrm{A}, \mathrm{in}}\left(1-y_{\mathrm{A}, \mathrm{in}}-y_{\mathrm{B}, \mathrm{in}}\right)\right)=R D a \frac{\Delta \theta_{\mathrm{ad}, \mathrm{R}}}{y_{\mathrm{Ain}}} \\
& +\frac{E \mu}{\theta} \Delta \theta_{\mathrm{ad}, \mathrm{A}}\left(\frac{\mathrm{d} y_{\mathrm{A}}}{\mathrm{d} z}+\frac{\mathrm{d} y_{\mathrm{B}}}{\mathrm{d} z}\right)
\end{aligned}
$$

with

$$
\delta=\frac{c_{\mathrm{p}, \mathrm{P}}^{\mathrm{s}}}{c_{\mathrm{pg}, \mathrm{in}}} \quad \text { and } \quad \Gamma_{\mathrm{p}}=\frac{c_{\mathrm{pg}}}{c_{\mathrm{pg}, \mathrm{in}}} .
$$

In these equations the following dimensionless groups 
have been introduced:

$$
\begin{aligned}
& D a=\frac{R_{\mathrm{P}, \mathrm{R}} \rho_{\mathrm{b}} S L}{\phi_{\mathrm{in}}}, \text { a Damköhler number } \\
& E=\frac{\phi_{\mathrm{s}} m_{\mathrm{R}}}{\rho_{\mathrm{s}} \phi_{\mathrm{in}} y_{\mathrm{A}, \text { in }}} \frac{p}{R_{\mathrm{g}} T_{\mathrm{R}}}, \text { an adsorption number }
\end{aligned}
$$

$\Delta \theta_{\mathrm{ad}, \mathrm{A}}=\frac{\left(-\Delta H_{\mathrm{A}}\right) y_{\mathrm{A}, \text { in }}}{c_{\mathrm{pg}, \text { in }} T_{\mathrm{R}}} \quad \begin{aligned} & \text { an adiabatic temperature } \\ & \text { rise by adsorption number }\end{aligned}$

$\Delta \theta_{\mathrm{ad}, \mathrm{R}}=\frac{\left(-\Delta H_{\mathrm{R}}\right) y_{\mathrm{A}, \text { in }}}{c_{\mathrm{pg}, \mathrm{in}} T_{\mathrm{R}}}, \quad \begin{aligned} & \text { an adiabatic temperature } \\ & \text { rise by reaction number }\end{aligned}$

and

$$
\beta=\frac{c_{\mathrm{ps}} \phi_{\mathrm{s}}}{c_{\mathrm{pg}, \text { in }} \phi_{\mathrm{in}}}, \quad \text { a heat capacitics ratio number. }
$$

The dimensionless boundary conditions follow from eqns (19)-(28); we now obtain for the bottom plane $Z=0$ :

$$
\begin{aligned}
& y_{\mathrm{Ao}}=y_{\mathrm{A}, \text { in }} \frac{1}{\psi_{\mathrm{o}}} \\
& y_{\mathrm{Bo}}=y_{\mathrm{B}, \text { in }} \frac{1}{\psi_{\mathrm{o}}} \\
& \psi_{\mathrm{o}}=1+\frac{\phi_{\mathrm{s}}\left(C_{\mathrm{P}, \mathrm{s}, \mathrm{o}}-C_{\mathrm{P}, \mathrm{s}, \mathrm{out}}\right)}{\rho_{\mathrm{s}} \phi_{\mathrm{in}}}
\end{aligned}
$$

with

$$
\begin{gathered}
C_{\mathrm{P}, \mathrm{s}, \mathrm{o}}=m\left(T_{\mathrm{o}}\right) \frac{p}{R_{\mathrm{g}} T_{\mathrm{o}}}\left(1-y_{\mathrm{Ao}}-y_{\mathrm{Bo}}\right) \\
\theta_{\mathrm{o}}=\theta_{\mathrm{s}, \text { out }}+\frac{\left(\psi_{\mathrm{o}}-1\right) \Delta \theta_{\mathrm{ad}, \mathrm{A}}}{\beta y_{\mathrm{A}, \text { in }}}+\frac{\left(\theta_{\mathrm{o}}-\theta_{\mathrm{gin}}\right)}{\beta}
\end{gathered}
$$

and for the top plane $Z=L$ :

$$
\begin{gathered}
y_{\mathrm{AL}}=\psi_{\text {out }} y_{\mathrm{A}, \text { out }} / \psi_{\mathrm{L}} \\
y_{\mathrm{BL}}=\psi_{\text {out }} y_{\mathrm{B}, \text { out }} / \psi_{\mathrm{L}} \\
\psi_{\mathrm{L}}=E y_{\mathrm{A}, \text { in }} \mu\left(\theta_{\mathrm{L}}\right) / \theta_{\mathrm{L}}+\psi_{\text {out }}\left(1-y_{\mathrm{A}, \text { out }}\right. \\
\left.-y_{\mathrm{B}, \text { out }}\right) /\left(1-y_{\mathrm{AL}}-y_{\mathrm{BL}}\right) \\
\theta_{\mathrm{L}}=\theta_{\mathrm{s}, \mathrm{in}}+\frac{\Delta \theta_{\mathrm{ad}, \mathrm{A}} E}{\beta} \frac{\mu\left(\theta_{\mathrm{L}}\right)}{\theta_{\mathrm{L}}}\left(1-y_{\mathrm{AL}} y_{\mathrm{BL}}\right) .
\end{gathered}
$$

\subsection{The relevant dimensionless groups}

The dependent variables are the mole fractions of the reactants $y_{\mathrm{A}}$ and $y_{\mathrm{B}}$, the temperature $\theta=T / T_{\mathrm{R}}$ and the dimensionless flow rate $\psi=\phi_{\text {tot }} / \phi_{\text {in }}$, while the independent variable is $z=Z / L$. The system is already completely described by three of the dependent variables. In the basic equations several dimensionless groups appear: the Damköhler number $\mathrm{Da}$; the adsorption number $E$, which expresses the ratio of the adsorption capacity of the solid fed and the maximum possible formation of the product; the adiabatic temperature rises $\Delta \theta_{\mathrm{ad}, \mathrm{R}}$ due to the heat of reaction and $\Delta \theta_{\mathrm{ad}, \mathrm{A}}$ due to the heat of adsorption, which are related to the molar heat capacity of the feed gas and express the exothermicity both of reaction and adsorption; the parameter $\beta$, which represents the ratio of the heat capacities of the solids and the gas streams; and $\Gamma_{\mathrm{p}}$ is the dimensionless heat capacity of the gas phase at the actual conditions (temperature, composition) in the reactor. We now discuss the significance of these groups.

The significance of the Damköhler number $D a$ is clear: it is the dimensionless residence time in the reactor, so that the total conversion will increase with increasing $D a$. The adsorption number $E$ determines the amount of product that will be adsorbed and the amount that will disappear over the top of the GSSTFR. Once the reaction system, the catalyst, the adsorbent and their properties are known, the main variables for the design and operation of a GSSTFR are $D a$ and $E$. For a desired conversion level and with no adsorbent flowing through the reactor, a certain value of $D a$ is required at a certain temperature level. If now at the same temperature level a stream of adsorbent flows through the reactor, the conversion will be increased if the value of $D a$ remains constant. It can be imagined that by ever increasing the solids flow, and therefore $E$, eventually complete conversion will be reached at the same $D a$ value and the same temperature level. A further increase of $E$ makes no sense. Vice versa, for a fixed value of $E$ and at the same temperature level by changing $\mathrm{Da}$ also full conversion can eventually be reached. So, at a given temperature level the combination of $E$ and $D a$ values determines the conversion reached: in principle, complete conversion is feasible.

All other dimensionless numbers play a minor or only a dependent role, or cannot be influenced by the designer or operator. The correct choice of the temperature level is the third variable of major importance. This is explained further in our discussion of the methanol synthesis as an example of the application of the GSSTFR principle. Temperature decreases in the downstream direction of the gas flow, provided the solids flow rate is sufficiently high. The significance of the dimensionless groups is discussed further in the Results.

\subsection{Method of solution of the set of equations}

To determine the concentration, flow and temperature profiles along the reactor length, the differential equations (29)-(31) and (33) have to be integrated simultaneously fulfilling the boundary conditions at both ends.

As input data, the values of $D a$ and $E$, the temperatures of the feed streams $\theta_{g, i n}$ and $\theta_{\mathrm{s}, \mathrm{in}}$, the feed gas composition and the desired key reactant conversion $\zeta_{\mathrm{A}}$, defined by

$$
\zeta_{\mathrm{A}}=\frac{y_{\mathrm{A} . \mathrm{in}}-y_{\mathrm{A}} \psi}{y_{\mathrm{A}, \mathrm{in}}}
$$

are taken. The input data describing the reactor operating conditions chosen do not define the start values $y_{\mathrm{Ao}}, y_{\mathrm{Bo}}, \psi_{\mathrm{o}}$ and $\theta_{\mathrm{o}}$ unequivocally: the reaction product distribution between the solid stream and the 
gaseous reactor effluent remains unknown, so that an iteration procedure becomes necessary. In our calculations (see Fig. 7), the product distribution ratio $\alpha$, defined as

$\alpha=\frac{\phi_{\text {out }} y_{\mathrm{P}, \text { out }}}{\phi_{\text {in }} y_{\mathrm{A}, \text { in }} \zeta_{\mathrm{A}}}=\frac{\phi_{\text {in }} y_{\mathrm{A}, \text { in }} \zeta_{\mathrm{A}}-\frac{\phi_{\mathrm{s}}}{\rho_{\mathrm{s}}} C_{\mathrm{P}, \text {, out }}}{\phi_{\text {in }} y_{\mathrm{A}, \text { in }} \zeta_{\mathrm{A}}}$

is subject to iteration. With eq. (48) and for the assumed value of $\alpha$, the product concentration in the solid, $C_{P . s, o u t}$, is found. Further, from eq. (28) the temperature $T_{\mathrm{L}}$ at the upper reactor end is determined assuming $\theta_{\text {gout }}=\theta_{\mathrm{L}}$. This latter assumption implies that there is at the top plane only a sudden temperature increase in the solids stream, whereas the gas leaves the reactor without a temperature change: this is reasonable in view of the large differences in heat capacities at the top of the reactor.

The temperature $\theta_{\mathrm{s}, \mathrm{out}}$ of the solid leaving the reactor is then found from the overall enthalpy balance:

$$
\begin{aligned}
\theta_{\text {s.out }}= & {\left[\beta \theta_{\mathrm{s}, \text { in }}-\zeta_{\mathrm{A}} y_{\mathrm{A}, \text { in }} \Gamma_{\mathrm{P}} \alpha \theta_{\mathrm{L}}-y_{\mathrm{A}, \text { in }} \Gamma_{\mathrm{A}}\left(\left(1-\zeta_{\mathrm{A}}\right) \theta_{\mathrm{L}}\right.\right.} \\
& \left.-\theta_{\mathrm{g}, \text { in }}\right)-\Gamma_{\mathrm{B}}\left(\left(1-y_{\mathrm{A}, \text { in }}\left(1-2 \zeta_{\mathrm{A}}\right)\right) \theta_{\mathrm{L}}\right. \\
& \left.-\left(1-y_{\mathrm{A}, \text { in }}\right) \theta_{\mathrm{g}, \text { in }}\right)+\zeta_{\mathrm{A}}\left(\Delta \theta_{\mathrm{ad}, \mathrm{R}}\right. \\
& \left.\left.+(1-\alpha) \Delta \theta_{\mathrm{ad}, \mathrm{A}}\right)\right] /\left[\beta+\zeta_{\mathrm{A}} y_{\mathrm{A}, \text { in }} \delta(1-\alpha)\right]
\end{aligned}
$$

with $\Gamma_{i}=\frac{c_{\mathrm{p}, i, i}}{c_{\mathrm{pg}, \text { in }}}$ for the components $\mathrm{A}, \mathrm{B}$ and $\mathrm{P}$. The lower end boundary conditions (39)-(43) are solved simultaneously to determine the start values $\psi_{0}, \theta_{0}, y_{\mathrm{A}}$ and $y_{B}$. The numerical integration is then initialized and continued until the required the value $\zeta_{A}$ is reached: we use the Runge-Kutta-Merson integration procedure. The resulting distribution ratio $\alpha_{o b t}$ at the point where the desired value of $\zeta_{A}$ is reached is then calculated from

$$
\alpha_{\mathrm{obt}}=\frac{\left(1-y_{\mathrm{A}}-y_{\mathrm{B}}\right) \psi}{y_{\mathrm{A}, \mathrm{in}} \zeta_{\mathrm{A}}}
$$

and compared with the originally assumed $\alpha_{\text {as }}$ value. If the criterion

$$
\frac{\left(\alpha_{\text {as }}-\alpha_{\text {obt }}\right)}{\alpha_{\text {obt }}}<0,001
$$

is not fulfilled, the integration procedure is reinitialized substituting the last-obtained value of $\alpha_{\text {abt }}$ for $\alpha_{\text {as }}$. Also the value of the Damköhler number is adjusted in the iteration cycle: if the required value of $\zeta_{\mathrm{A}}$ is already reached at a location $z<1$, in the next integration as the new $D a$ value we take

$$
D a_{\text {new }}=z D a_{\text {previous }} \text {. }
$$

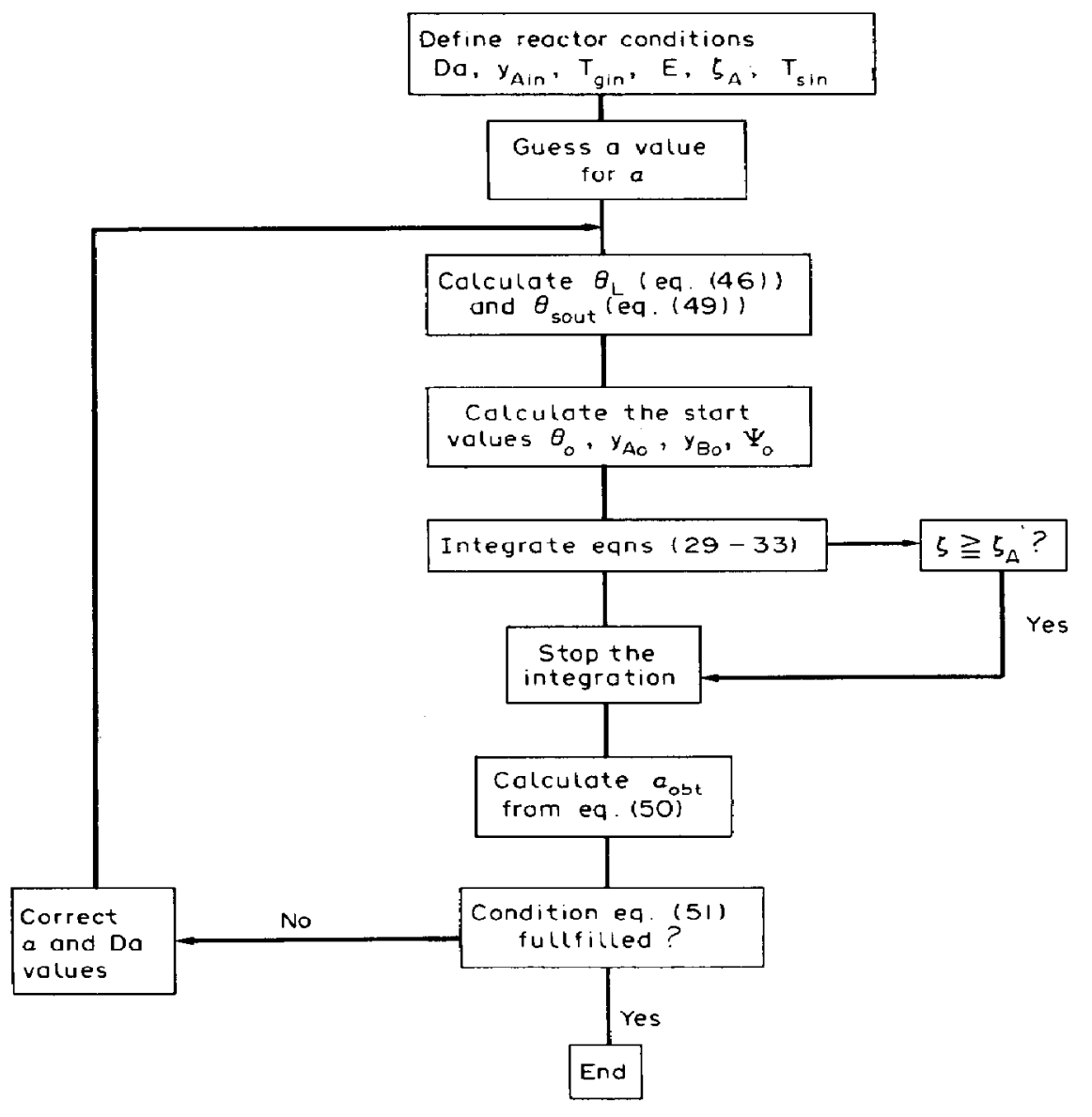

Fig. 7. The calculation procedure. 
If, on the other hand, the required value of $\zeta_{A}$ has not yet been reached at $z=1$, the integration procedure is reinitialized using $D a_{\text {new }}=1.5 D a_{\text {previous. }}$. With this solution procedure it is our experience that around 6-10 iterations are necessary to obtain the required accuracy.

We now apply the model outlined to the synthesis of methanol from $\mathrm{CO}+\mathrm{H}_{2}$.

\section{THE METHANOL SYNTHESIS}

\subsection{Reaction system}

In the following paper the experimental work on the methanol synthesis will be described, in which the synthesis gas was free of carbon dioxide and inert gases. In the process studied, a mixture of carbon monoxide and hydrogen over a copper catalyst is converted into methanol, according to

$$
\begin{aligned}
\mathrm{CO}+\mathrm{H}_{2}=\mathrm{CH}_{3} \mathrm{OH} & \\
& -\Delta H_{\mathrm{R}}(298 \mathrm{~K})=91 \mathrm{~kJ} \mathrm{~mol}^{-1} .
\end{aligned}
$$

A commercial silica-alumina fluid cracking catalyst is used as the adsorbent for methanol. We now will apply the basic equations derived to describe the behaviour of the GSSTF reactor to the synthesis of methanol.

\subsection{Basic data}

The reaction kinetics of the methanol synthesis can be represented by (Kuczynski et al., 1986a):

$$
\begin{array}{r}
R_{\mathrm{P}}=\frac{k\left[\Psi_{\mathrm{CO}} \Psi_{\mathrm{H}_{2}}^{2}-\Psi_{\mathrm{CH}_{3} \mathrm{OH}} / K_{\mathrm{eq}}\right]}{\left[1+K_{\mathrm{CO}} \Psi_{\mathrm{CO}}+K_{\mathrm{H}_{2}} \Psi_{\mathrm{H}_{2}}+K_{\mathrm{CH}_{3} \mathrm{OH}} \Psi_{\mathrm{CH}_{3} \mathrm{OH}}\right]^{3}} \\
\left(\mathrm{~mol} \mathrm{C \textrm {CH } _ { 3 } \mathrm { OH } ) ( \mathrm { kg } \mathrm { cat } \mathrm { s } ) ^ { - 1 }}\right. \text { (54) }
\end{array}
$$

where $\Psi_{\mathrm{CO}}, \Psi_{\mathrm{H}_{2}}$ and $\Psi_{\mathrm{CH}_{3} \mathrm{OH}}$ are the component fugacities (pressure activities) divided by the standard state pressure of $0.1 \mathrm{MPa}$. The values of the parameters $k, K_{\mathrm{CO}}, K_{\mathrm{H}_{2}}$ and $K_{\mathrm{CH}_{3} \mathrm{OH}}$ are given in Table 1. The component fugacities can be calculated from

$$
\Psi_{i}=y_{i} p f_{i}
$$

where $f_{i}$ is the fugacity coefficient of component $i$ in the gas mixture. The calculation method of $f_{i}$ is described elsewhere (Kuczynski et al., 1986a). The true equilibrium constant $K_{\text {eq }}$ for the methanol synthesis is calculated from

$$
\ln K_{\mathrm{eq}}=-28.9762+11815 /(T / \mathrm{K}) \text {. }
$$

Elsewhere (Kuczynski et al., 1986b) we have reported

Table 1. Values of the parameters in the rate equation (54) for the methanol synthesis: $k_{i}=A_{\infty} \exp \left(\frac{-E_{i}}{R_{\mathrm{g}} T}\right)$ (Kuczynski et al., 1986a)

\begin{tabular}{lccr}
\hline Parameter & \multicolumn{1}{c}{$A_{\alpha}$} & Units & $\begin{array}{r}E_{i} / R_{\mathrm{g}} \\
(\mathrm{K})\end{array}$ \\
\hline $\boldsymbol{k}$ & $1.67 \times 10^{9}$ & mol (kg cat s) & \\
$K_{\mathrm{CO}}$ & 13.5 & - & 17,680 \\
$K_{\mathrm{H}_{2}}$ & 4.51 & - & 2600 \\
$K_{\mathrm{CH}, \mathrm{OH}}$ & 0 & - & 2710 \\
\hline
\end{tabular}

on the experimental determination of the methanol adsorption capacity of the amorphous silica-alumina cracking catalyst. The adsorption isotherms for the temperature range of interest are shown in Fig. 8. A linear fit of the experimental equilibrium curves gives for the distribution coefficient $m=m_{\infty} \exp \left(T_{\mathrm{m}} / T\right)$, the following parameter values: $m_{\omega}=0.145\left(\mathrm{~mol} \mathrm{~m}^{-3}\right.$ solid $) /\left(\mathrm{mol} \mathrm{m}^{-3}\right.$ gas) and $T_{\mathrm{m}}=2304 \mathrm{~K}$. Beyond a certain partial pressure no more methanol is adsorbed: the solid is saturated. This maximum adsorption capacity as a function of the temperature has been correlated by

$$
C_{\mathrm{P}, \mathrm{s}}^{\mathrm{sat}}=81.8 \exp 1753 /(T / \mathrm{K}) \quad \mathrm{mol} \mathrm{P} \mathrm{m}^{-3} \text { solid. }
$$

In Fig. 8 the linear approximations of the adsorption isotherms are also shown. The heat of adsorption $\Delta H_{\mathrm{A}}$ is independent of the temperature and equals $-6430 \mathrm{~J} \mathrm{~mol}^{-1}$ (Kuczynski et al., 1986b).

The particle density of the solid is $813 \mathrm{~kg} \mathrm{~m}^{-3}$ and the mean particle diameter amounts to $90 \times 10^{-6} \mathrm{~m}$ (Westerterp and Kuczynski, 1987). For the reference temperature $T_{\mathrm{R}}$, a value of $542.2 \mathrm{~K}$ has been chosen, this being the temperature at which the equilibrium reactant conversion equals $50 \%$ for a stoichiometric mixture of $\mathrm{CO}$ and $\mathrm{H}_{2}$ at $6 \mathrm{MPa}$. At $T_{R}$ we find $R_{P, R}$ $=0.012 \mathrm{~mol} \mathrm{CH}{ }_{3} \mathrm{OH}(\mathrm{kg} \text { cat s})^{-1}$ and $m_{\mathrm{R}}=10.15$ (mol $\mathrm{CH}_{3} \mathrm{OH} \mathrm{m} \mathrm{m}^{-3}$ solid)/( $\mathrm{mol} \mathrm{CH}_{3} \mathrm{OH} \mathrm{m}^{-3}$ gas). For $c_{\mathrm{pg}, i}$ and $c_{\mathrm{ps}}$ literature data (Reid et al., 1977; LandoltBörnstein, 1969) were used. Owing to lack of original data, we assumed the molar heat capacity of the adsorbed methanol to be equal to the heat capacity of gaseous methanol.

We also have to check whether under normal operating conditions for the methanol synthesis in a GSSTFR the mass-transfer resistances and axial dispersions can be neglected.

For mass transfer between the bulk of the gas and the adsorbent particles we find for $S h=2$ (Ranz and Marshall, 1952) that $k_{\mathrm{g}} a=2 D a / d_{\mathrm{p}}$. With $a=6$ $\beta_{\mathrm{dyn}} / d_{\mathrm{p}}$, taking $\beta_{\mathrm{dyn}}=0.02$ and $d_{\mathrm{p}}=90 \times 10^{-6} \mathrm{~m}$ (Westerterp and Kuczynski, 1987) and for the diffusivity of methanol in a $\mathrm{CO}-\mathrm{H}_{2}$ mixture at $6.5 \mathrm{MPa}$

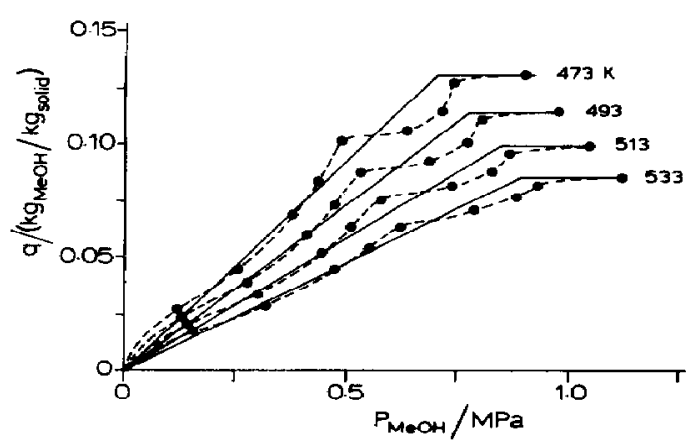

Fig. 8. Methanol adsorption equilibrium isotherms for 473-533 K. Adsorbent: LA-25 low alumina cracking catalyst. - - Experimental isotherms (Kuczynski et al., 1986b); - linear approximation and saturation leve]. 
and $540 \mathrm{~K}$ a value of $D=1.3 \times 10^{-6} \mathrm{~m}^{2} \mathrm{~s}^{-1}$ (Reid et al., 1977; Landolt-Börnstein, 1969), we obtain $k_{\mathrm{g}} a$ $=38 \mathrm{~s}^{-1}$. So for a linear gas velocity $u_{\mathrm{g}}=0.01 \mathrm{~m} \mathrm{~s}$ the height of a mass-transfer unit is $H_{k}=0.26$ $\times 10^{-3} \mathrm{~m}$. For a linear velocity of the solids stream of $0.17 \mathrm{~m} \mathrm{~s}^{-1}$, we estimate using the work of Roes (1978) $B o_{\mathrm{s}}=0.12$ and $B o_{\mathrm{g}}=0.05$ for a column packed with Pall rings. For $d^{*}=5 \times 10^{-3} \mathrm{~m}$, we then calculate $L / P e_{s}=0.004 \mathrm{~m}$ and $L / P e_{\mathrm{g}}=0.1 \mathrm{~m}$. For a stoichiometric synthesis gas and assuming first-order kinetics with respect to $\mathrm{CO}$, the kinetic constant $k$ in eq. (6) can be estimated. For the process conditions mentioned and for $\rho_{\mathrm{b}}=1000 \mathrm{~kg} \mathrm{~m}^{-3}$, we obtain $\mathrm{HRU}=1.17 \mathrm{~m}$. So the condition $\mathrm{HRU} \gg H_{\mathrm{k}}, L / P e_{\mathrm{g}}$ and $L / P e_{\mathrm{s}}$ is fulfilled, so that indeed we can neglect axial dispersion and mass-transfer resistances in applying our model to the low-pressure methanol synthesis.

\section{RESULTS}

The computations were made on a HewlettPackard model 9826 personal technical computer. In Fig. 9 the profiles calculated are shown for the GSSTFR operating under a pressure of $6 \mathrm{MPa}$ and fed with a stoichiometric reactant mixture. It appears that at sufficiently high $D a$ values complete conversion is attainable, the driving force for the reaction remaining high over the entire catalyst bed. For a stoichiometric synthesis gas mixture and at full conversion the reactor effluent flow decreases to zero - there is no inert and no excess reactant present. In this case, the solids stream is the only medium that removes both the product and the heat of reaction and adsorption from the adiabatic GSSTFR. We see that from top to bottom the temperature in the reactor increases continuously. The temperature increase is relatively modest because of the high solids flow (high value of $E$ ). Due to the high solids flow, also the methanol content of the gas phase remains low so that the reaction rate keeps increasing despite the temperature increase. A slight decrease of $E$ of $5 \%$ already gives too high temperatures in the reactor bottom, which causes the reaction rates to slow down. A maximum in the reaction rate is observed in Fig. 10; this is a combined effect on the reaction kinetics of the temperature and of the conversion achieved. For a stoichiometric feed gas composition, the integration cannot be continued up to complete conversion because $\psi$ approaches zero and divergence occurs. So we stopped the integration at $0.995 \leqslant \zeta_{\mathrm{A}}<1$.

At higher values of the adsorption number $E$ (cf. Figs 9 and 11) the methanol concentration in the column and at the reactor bottom outlet decreases. Consequently the driving force for the reaction increases. An increase in $E$ also leads to a reduction of the temperature rise in the reactor as a result of the higher heat absorbing capacity of the increased solids stream. This may result either in a capacity increase or decrease for the reactor. An increase of $E$ by a factor of 1.5 led to a $15 \%$ decrease of the reactor capacity for the cases represented in Figs 9 and 11.

In practice it may be difficult to maintain the feed gas exactly at the stoichiometric composition. Therefore we demonstrate in Fig. 12 how the GSSTF reactor will behave if a slight deviation in $y_{A, \text { in }}$ occurs; steady-state profiles are shown for $y_{\mathrm{A}, \mathrm{in}}=\mathbf{0 . 3 0}$ and other conditions unchanged. Complete $\mathrm{CO}$ conversion is attained; the
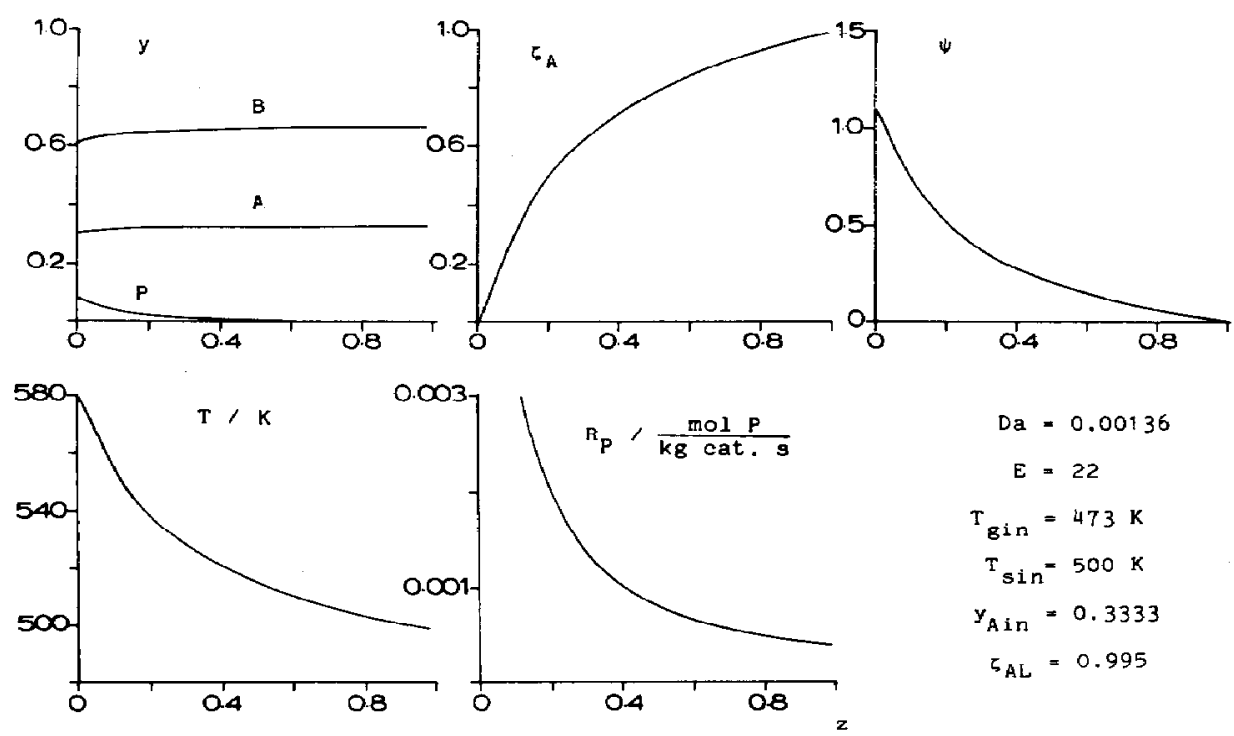

$$
\begin{aligned}
D a & =0.00136 \\
E & =22 \\
T_{\text {Bin }} & =473 \mathrm{~K} \\
T_{\text {sin }} & =500 \mathrm{~K} \\
y_{A \text { in }} & =0.3333 \\
5_{A L} & =0.995
\end{aligned}
$$

Fig. 9. Profiles in the countercurrent GSSTFR as calculated. On the top row from left to right: (a) the molar fractions in the gas phase; (b) the overall CO conversion; and (c) the dimensionless gas flow. On the bottom row: (d) the temperature; (e) the reaction rate in mol MeOH $\left(\mathrm{kg} \mathrm{cat} \mathrm{s}^{-1}\right.$, all as a function of the dimensionless reactor length. Here, $z=0$ is the bottom and $z=1$ is the top of the GSSTF reactor. The basic data used for the calculations are also given on the bottom row. 

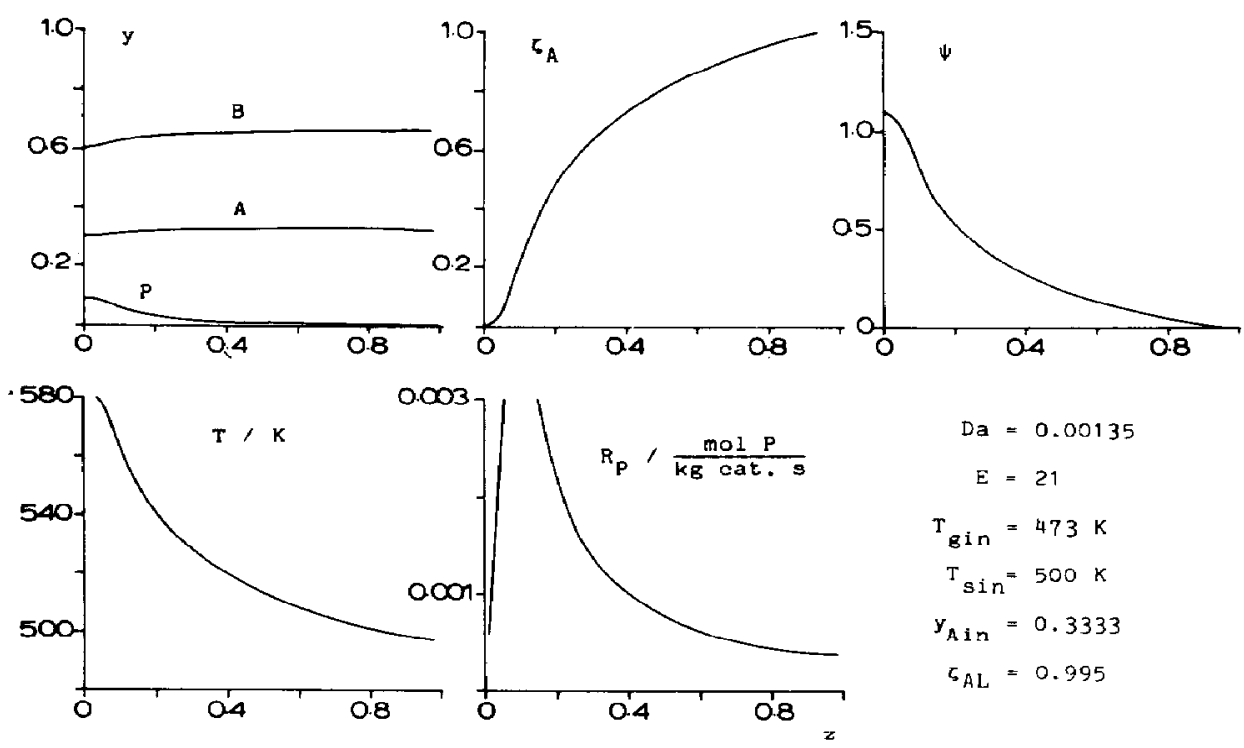

$$
\begin{aligned}
D a & =0.00135 \\
E & =21 \\
T_{\text {Bin }} & =473 \mathrm{~K} \\
T_{\text {Sin }} & =500 \mathrm{~K} \\
y_{\text {Ain }} & =0.3333 \\
5_{\text {RL }} & =0.995
\end{aligned}
$$

Fig. 10. Steady-state profiles at $E=21$. For an explanation, see Fig. 9 .
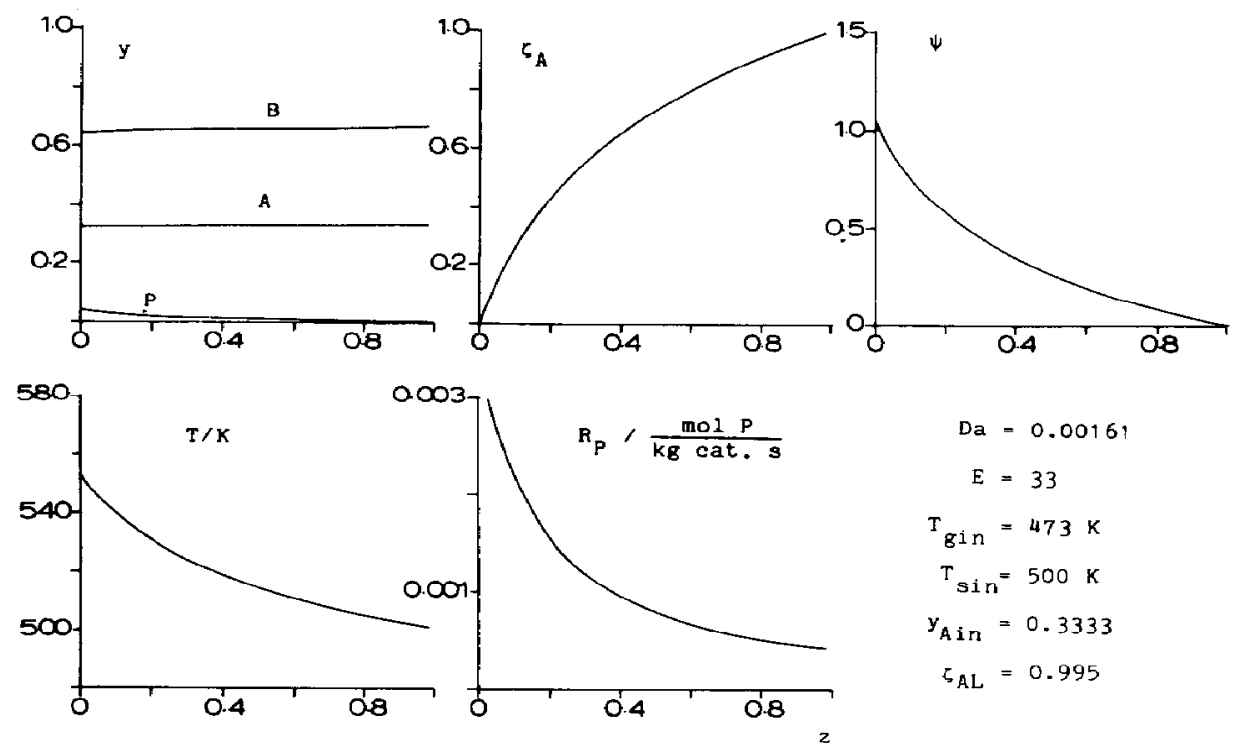

$$
\begin{aligned}
D_{a} & =0.00161 \\
E & =33 \\
T_{\text {gin }} & =473 \mathrm{~K} \\
T_{\text {Sin }} & =500 \mathrm{~K} \\
y_{\text {Ain }} & =0.3333 \\
\zeta_{\text {AL }} & =0.995
\end{aligned}
$$

Fig. 11. Reactor performance at $E=33$. For an explanation, see Fig. 9.

excess hydrogen leaves the reactor at the top. A similar effect can be expected in the case where there are inerts present in the reactor.

Since the reaction kinetics are strongly temperaturedependent, the reactor temperature should be kept at an optimum level. This can be effected in three different ways, apart from choosing the correct inlet temperatures:

(1) by increasing of the heat capacity ratio $\beta$; that is, increasing the solids feed flow. Then $E$ also increases (cf. Figs 9 and 11);
(2) by intermediate cooling between reactor sections. In Fig. 13 the profiles are shown for a reactor equipped with three intermediate coolers: the temperatures are maintained between 500 and $540 \mathrm{~K}$;

(3) by cooling through tube walls. The reactor is now of the heat exchanger type with the cooling medium around the packed tubes, like, for example, the Lurgi methanol reactor (Supp, 1981). The profiles are illustrated in Fig. 14; the reactor now operates almost isothermally. 

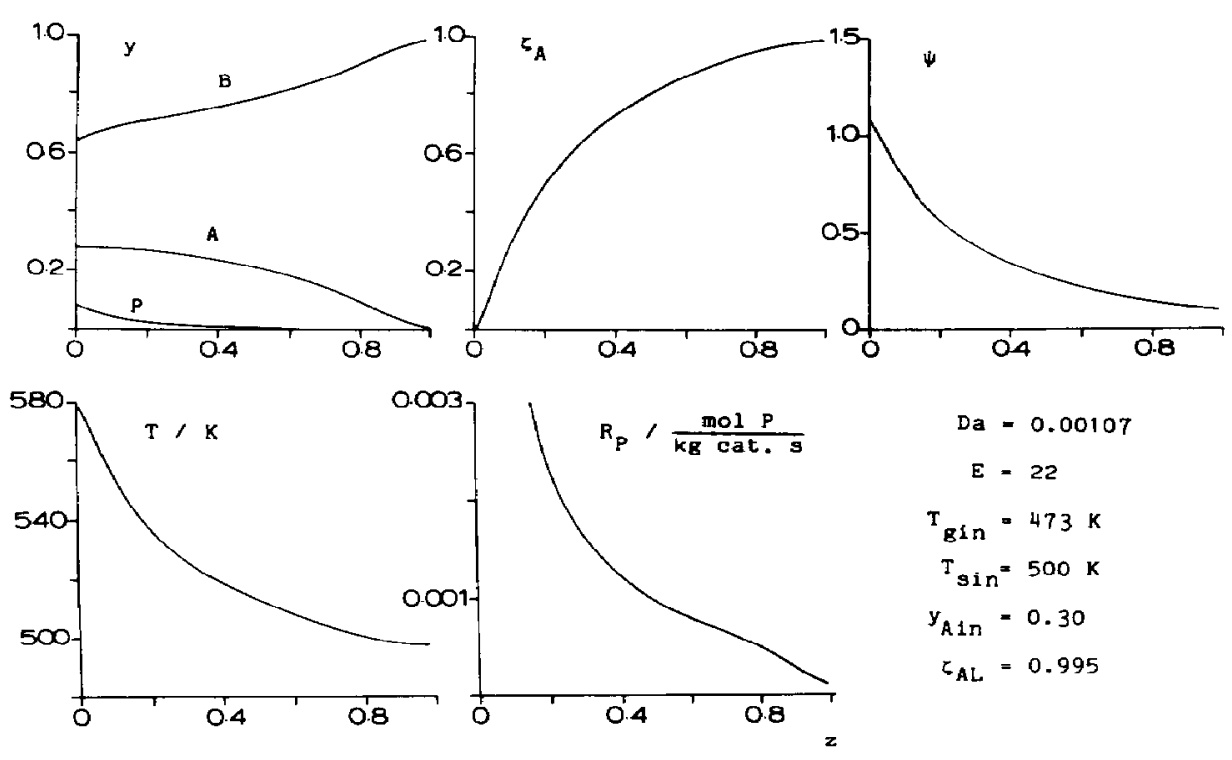

$$
\begin{aligned}
\text { Da } & =0.00107 \\
E & =22 \\
T_{\text {gin }} & =473 \mathrm{~K} \\
T_{\text {Sin }} & =500 \mathrm{~K} \\
\mathrm{Y}_{\text {A1 }} & =0.30 \\
\tau_{\text {AL }} & =0.995
\end{aligned}
$$

Fig. 12. Steady-state profiles for $y_{\mathrm{A}, \text { in }}=0.30$. For an explanation, see Fig. 9.
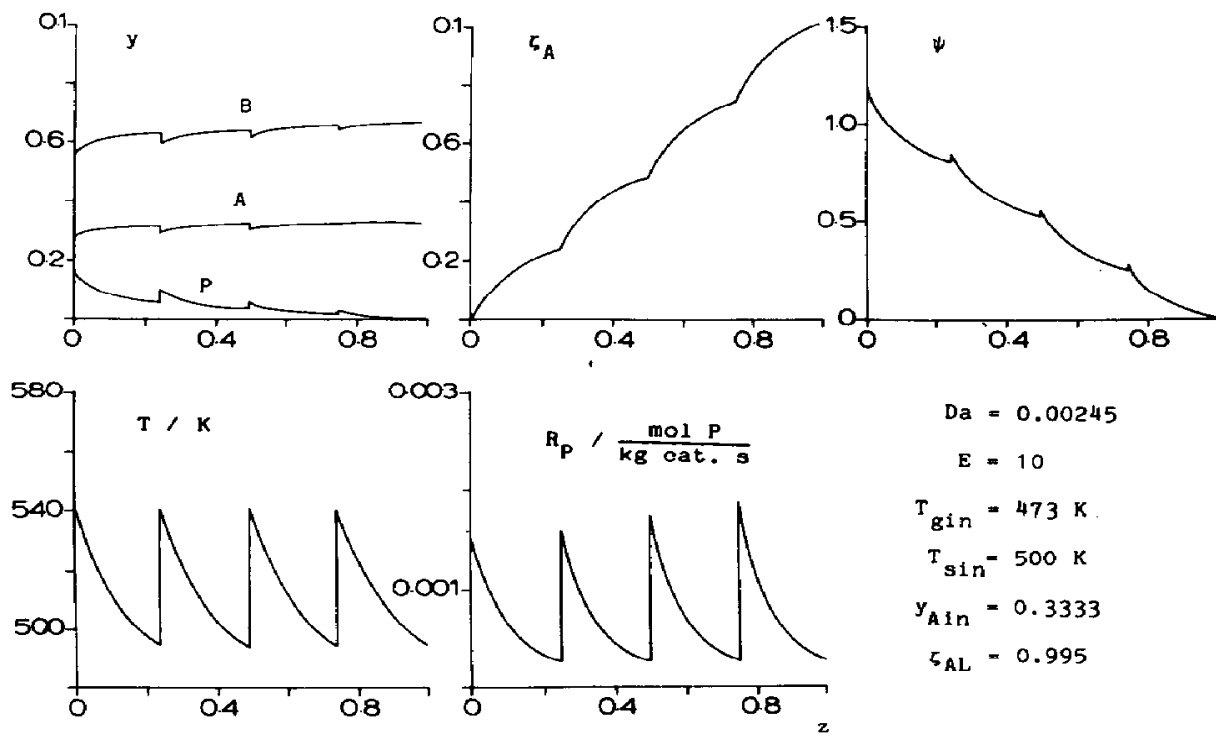

$$
\begin{aligned}
D a & =0.00245 \\
E & =10 \\
T_{\text {gin }} & =473 \mathrm{~K} \\
T_{\text {sin }} & =500 \mathrm{~K} \\
\mathrm{Y}_{\text {A In }} & =0.3333 \\
5_{\mathrm{AL}} & =0.995
\end{aligned}
$$

Fig. 13. The profiles in a GSSTFR equipped with three intermediate coolers. For an explanation, see Fig. 9.

The method of cooling chosen depends largely on the economics. In the following, we demonstrate that adiabatic reactor sections with intermediate coolers probably provide the most economic solution.

\section{Discussion}

From the results of the calculations for the methanol synthesis it can be seen that the most important variables determining the performance of the GSSTFR are $D a, E$ and the temperature level. We now compare the different options available for design engineers.

It is easiest to compare isothermal reactors. In Fig. 15 the required $D a$ number is given as a function of the desired conversion and of the reactor temperature. Two cases are represented in this figure, one for $500 \mathrm{~K}$ and the other for $540 \mathrm{~K}$, which are about the extremes for efficient reactor operation for the methanol synthesis. For the low temperature a maximum conversion of $75 \%$ can be reached at a high $\mathrm{Da}$ value. If the reactor temperature is increased by $40 \mathrm{~K}$, the reactor capacity increases 3-5-fold, but now a maximum conversion of only $50 \%$ can be reached. This is a well-known property of an isothermal tubular reactor for equilibrium reactions.

We now compare the two isothermal reactors both operating at $500 \mathrm{~K}$, but now operating according to the 


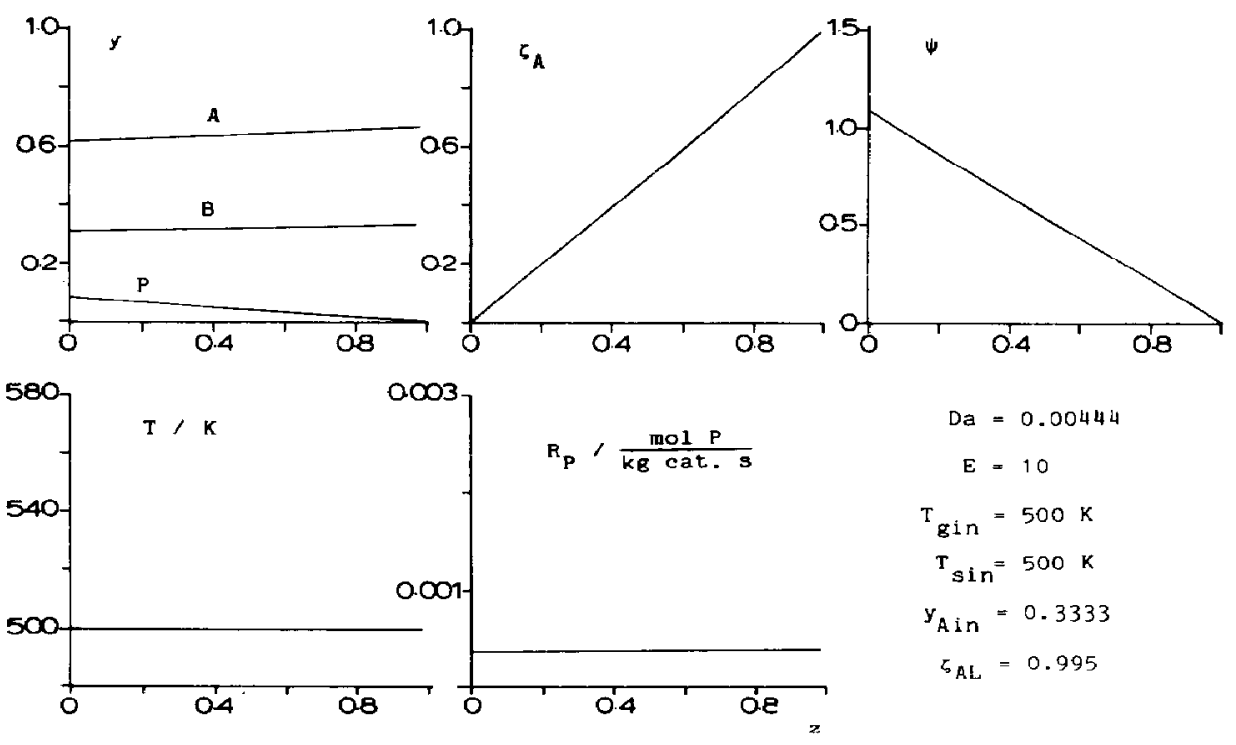

Fig. 14. An isothermal GSSTFR. For an explanation, see Fig. 9.

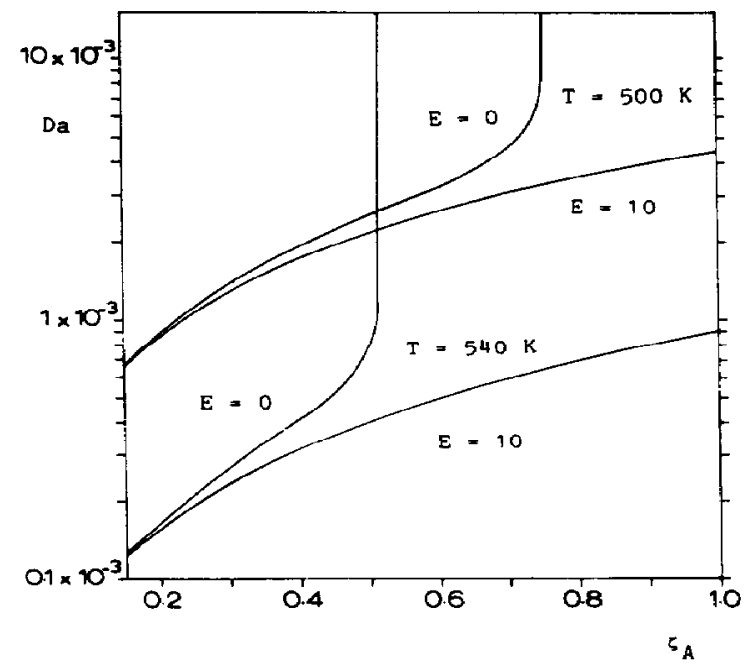

Fig. 15. $D a$ vs. $\zeta_{A}$ curves for an isothermal GSSTFR at $E=0$ and $E=10$.

GSSTFR principle with $E=10$. We see that at low conversions the capacity is hardly improved, whereas great gains are obtained in the neighbourhood of equilibrium conversions and above. For example, if at the same flow rate the mass of catalyst is increased by $50 \%$, the conversion is increased from 67 to $100 \%$ for $E=10$. Also with the same mass of catalyst and the same flow rate, the conversion can be increased from 69 to $100 \%$ if product is adsorbed with $E=10$. At low conversion levels and with $E=10$, the required $D a$ is hardly decreased with respect to the case without adsorbent flow $(E=0)$, because there the backward reaction does not have much influence yet and the concentrations of the product in the gas phase are still low. At higher conversion levels, the product concen- trations in the bottom part of the reactor become considerable and reaction rates are slowed down in that area. In the case of full conversion and $E=10$, $T=500 \mathrm{~K}$, the solid contains 5.3 mass $\%$ of methanol. This is a rather low methanol content because it would imply a recycle ratio of 19 ton solids circulated per ton of methanol produced. In practice, an operator would aim for the lowest value possible for $E$ : at $500 \mathrm{~K}$ for full conversion this is $E=\mathbf{4 . 9}$ for our adsorbent giving a recycle ratio of 9.3 , this being the reciprocal mass fraction of methanol $(0.108)$ on the outflowing solid stream. The mass of catalyst has to be increased by $13 \%$ in that case.

If we now compare both cases for $E=10$, but at the two different temperature levels, we see that at full conversion the capacity of the reactor is 4.8 times higher at the high temperature of $540 \mathrm{~K}$. However, in this case at the higher temperatures the adsorption capacity of the powder is lower: the maximum adsorption is reached at $E=7.9$, in which case the outflowing solid contains 6.7 mass \% of methanol, giving a recycle ratio of 15 . We see that the high reactor capacity at a higher temperature level has to be acquired at the expense of a high solids recycle ratio. This will hardly be cconomical, so that in practice the GSSTFR has to be operated at relatively low temperature levels.

Another aspect is the method of cooling. As mentioned above, we have to aim at the lowest possible values of $E$ in order to reduce the solids recycle in the plant. This leaves out improvement of the cooling by increasing $\beta$, i.e. by the solids load. This still leaves a choice between a cooled tubular reactor which operates almost isothermally - also because of the improvement of the radial heat transport due to the solids trickle flow-or adiabatic reactor sections with cooling sections in between. It can readily be understood that it is much more difficult to distribute a solids stream evenly in equal parts over a multitude of parallel 
reactor tubes than over one single bed of a large diameter. We are therefore convinced that adiabatic reactor sections with intermediate cooling are the only practical approach to the GSSTFR principle. This leaves the question of the number of cooling sections and of the temperature level to be applied. This is a matter of economics. Firstly, it must be stated that it is always wise to cool the solids stream after leaving the bottom and before being contacted with fresh gas, because this improves the adsorption of methanol and prevents the stripping off of the solids by the lean gas. Secondly, the capacity of the GSSTFR with adiabatic sections and intermediate cooling is higher than that of the isothermal reactor. The reactor represented in Fig. 13 has a capacity 1.75 times higher than the isothermal reactor operating at $E=10$ and $540 \mathrm{~K}$. It can be calculated for the case of Fig. 13 that the lowest possible value is $E=8.7$, for which a recycle ratio of 16.5 is requied. An additional intermediate cooler would allow a recycle ratio of 15.1 and still another intermediate cooler, i.e. five in total, a ratio of 14.1. More intermediate coolers reduce the solids recycle ratio in the plant, as also does lowering of the temperature level.

In order to increase the reactor capacity, the cooling in the top of the reactor should be less intense than in the bottom because in the upper part the methanol concentrations are low. In the lower part the temperature should be low in order to decrease the methanol concentrations in the gas phase. Therefore a temperature profile, in which the temperature level increases in the upward direction, will give the best results. An optimization procedure has to be developed for the purpose of finding the best temperature profile and the optimum number of intermediate coolers.

Another important aspect is the feed composition. In the calculations presented, in most cases we chose a stoichiometric composition of $1 / 3 \mathrm{CO}$ and $2 / 3 \mathrm{H}_{2}$. This is not a necessary requirement; in this way we only achieve that no gas leaves the reactor. In producing synthesis gas, mostly the excess $\mathrm{H}_{2}$-after all the $\mathrm{CO}$ has been converted-can be removed for use elsewhere in the factory or an amount of $\mathrm{CO}_{2}$, which can usually be made available at low cost, can be added to the synthesis gas to compensate for the excess $\mathrm{H}_{2}$, so that again the feed can be completely converted, now containing methanol and water as well.

\section{CONCLUSIONS}

A mathematical description has been given of the gas-solid-solid trickle flow reactor for equilibrium reactions. It has been shown that this reactor in principle must be capable of achieving complete conversion of the feed gas to product despite the unfavourable equilibrium. We further argued that the best and most economic operation of the GSSTFR will be achieved in a reactor consisting of adiabatic sections with cooling in between, operating at relatively low temperature levels and at the lowest possible solids flow rates. In the following paper we will describe experiments in a mini-plant with such a reactor and will confirm experimentally the model developed in this paper.

Acknowledgements - We are grateful to the Twente University of Technology and to the Royal Dutch Shell Group for financial support.

\section{NOTATION}

$A_{\infty} \quad$ pre-exponential factor (Table 1)

$a \quad$ specific surface area, $\mathrm{m}^{2} / \mathrm{m}^{3}$

Bo Bodenstein number, $\frac{u_{\mathrm{g}} d_{\mathrm{p}}}{\varepsilon D_{\mathrm{L}}}$

C concentration, $\mathrm{mol} \mathrm{m}^{-3}$

$c_{\mathrm{p}} \quad$ heat capacity, $\mathbf{J} \mathrm{mol}^{-1} \mathrm{~K}^{-1}$

$c_{\mathrm{ps}}$

solids heat capacity, $\mathrm{J} \mathrm{kg}^{-1} \mathrm{~K}^{-1}$

$\begin{array}{ll}D & \text { diffusivity, } \mathrm{m}^{2} \mathrm{~s}^{-1} \\ D a & \text { Damköhler number }\end{array}$

$\begin{array}{ll}D a & \text { Damkohler number } \\ D_{\mathrm{L}} & \text { effective axial diffusivity, } \mathrm{m}^{2} \mathrm{~s}^{-1}\end{array}$

$d^{*} \quad$ diameter of a packing particle, $\mathrm{m}$

$d_{\mathrm{p}} \quad$ particle diameter, $\mathrm{m}$

$E, E_{\mathrm{F}} \quad$ adsorption number

$E_{i}$

$-\Delta H_{\mathrm{A}}$ heat of adsorption per mol $\mathrm{P}$ adsorbed, $\mathrm{J} \mathrm{mol}^{-1}$

$-\Delta H_{\mathrm{R}}$ heat of reaction per mol $\mathrm{P}$ produced, $\mathrm{J} \mathrm{mol}^{-1}$

$H_{\mathrm{k}} \quad$ true height of a mass-transfer unit, $m$

$H_{\text {ov }}$ height of an overall transfer unit, $m$

HRU height of a reaction unit, $m$

$K \quad$ equilibrium constant

$k \quad$ kinetic constant, $\mathrm{mol}(\mathrm{kg} \text { cat s) })^{-1}$ or $\mathrm{s}^{-1}$

$k_{\mathrm{g}} \quad$ mass-transfer coefficient in gas phase, $\mathrm{m} \mathrm{s}^{-1}$

$\mathrm{g} \quad$ reactor length, $\mathrm{m}$

$m$ adsorption equilibrium factor $\left(\mathrm{mol} \mathrm{m}^{-3}\right.$ solid)/( $\mathrm{mol} \mathrm{m}^{-3}$ gas)

$m_{\text {cat }} \quad$ catalyst mass, $\mathrm{kg}$

$m_{\text {tot }} \quad$ total mass of the catalyst, $\mathrm{kg}$

$p \quad$ total pressure, $\mathrm{Pa}$

$q$ adsorption capacity, $\mathrm{kg} / \mathrm{kg}$ adsorbent

$P e \quad$ Peclet number, $\frac{u L}{\varepsilon D_{\mathrm{L}}}$

$R$ dimensionless reaction rate $\left(R_{\mathrm{P}} / \boldsymbol{R}_{\mathrm{P}, \mathrm{R}}\right)$

$R_{\mathrm{g}} \quad$ gas constant, equal to $8.3144, \mathrm{~J} \mathrm{~mol}^{-1} \mathrm{~K}^{-1}$

$R_{\mathrm{P}} \quad$ production rate, $\mathrm{mol} P$ produced $(\mathrm{kg} \text { cat } \mathrm{s})^{-1}$

$\boldsymbol{R}_{\mathrm{P}, \mathrm{R}} \quad$ production rate at reference temperature, mol $P$ produced $(\mathrm{kg} \text { cat } \mathrm{s})^{-1}$

cross-sectional area of the reactor, $\mathbf{m}^{2}$

\section{$T$}

$T_{\mathrm{m}}$

$u$

Sherwood number, $\frac{k_{\mathrm{g}} d_{\mathrm{p}}}{D}$

absolute temperature, $\mathrm{K}$

activation temperature for the adsorption, $K$

linear approach velocity, based on an empty cross-section, $\mathrm{m} \mathrm{s}^{-1}$

$v \quad$ molar volume, $\mathrm{m}^{3} \mathrm{~mol}^{-1}$

$y \quad$ molar fraction in the gas phase

$z$ dimensionless coordinate in gas flow

direction

coordinate in gas flow direction, $\mathrm{m}$ 


\section{Greek letters}

$\alpha \quad$ product distribution ratio

$\beta \quad$ heat capacity ratio [see eq. (38)]

$\Gamma$ dimensionless heat capacity of the gas [see eq. (33)]

$\delta$ dimensionless heat capacity of product absorbed [see eq. (33)]

$\varepsilon \quad$ void fraction

$\zeta \quad$ conversion

$\theta$ dimensionless temperature $\left(T / T_{\mathrm{R}}\right)$

$\Delta \theta_{\mathrm{ad}, \mathrm{R}}$ dimensionless temperature rise due to the reaction

$\Delta \theta_{\mathrm{ad}, \mathrm{A}}$ dimensionless temperature rise due to the adsorption

$\mu$ dimensionless adsorption factor, $m / m_{\mathrm{R}}$ or dynamic viscosity, $\mathbf{P a}$ s

$v \quad$ stoichiometric coefficient

$\rho$ density, $\mathbf{k g ~ m}^{-3}$

$\rho_{b} \quad$ bulk density of the catalyst, $\mathrm{kg} \mathrm{m}^{-3}$

$\phi \quad$ molar gas flow rate, mol s$^{-1}$

$\phi_{\mathrm{s}} \quad$ solids mass flow rate, $\mathrm{kg} \mathrm{s}^{-1}$

$\Psi \quad$ fugacity divided by the standard pressure

$\psi$ dimensionless gas flow rate $\left(\Phi_{\text {tot }} / \Phi_{\text {in }}\right)$

\section{Subscripts}

\section{A}

ass

B

eq

$\mathbf{g}$

i

j

in

L

o

obt

out

P

$\mathbf{p}$

$\mathbf{R}$

$\mathbf{s}$

\section{Superscripts}

$\begin{array}{ll}\text { s } & \text { adsorbed state } \\ \text { sat } & \text { saturated }\end{array}$

\section{REFERENCES}

Compagnie de Saint-Gobain 1965, French Patent No. 1.469.109.

Compagnie de Saint-Gobain 1978, French Patent Appl. Nos. 78/27054 and 78/27057, 27 Sept. 1978.

Directie van de Staatsmijnen in Limburg 1948, French Patent No. 978.287.
Kuczynski, M., Browne, W. I., Fontein, H. J. and Westerterp, K. R., 1986a, Reaction kinetics for the synthesis of methanol from $\mathrm{CO}$ and $\mathrm{H}_{2}$ on a copper catalyst. Chem. Engng Proc. (in press).

Kuczynski, M., van Ooteghem, A. and Westerterp, K. R.. 1986b, Methanol adsorption by amorphous silica alumina in the critical temperature range. Colloid Polymer Sci. 264, 362-367.

Kuczynski, M., Oyevaar, M. H., Pieters, R. T. and Westerterp. K. R., 1987, Methanol synthesis in a countercurrent gas-solid-solid trickle flow reactor. An experimental study. Chem. Engng Sci. 42, 1887-1898.

Landolt-Börnstein, 1969, Zahlenwerte und Funktionen 6, Aufl. Bd II/2a. Springer, Berlin.

Large, J. F., Naud, M., Guigon, P. and Bergougnou, M. A., 1981, Hydrodynamics of the raining packed-bed gas-solids heat exchanger. Chem. Engng J. 22, 95-100.

Noordergraaf, I. W., Roes, A. W. M. and van Swaaij, W. P. M., 1980a, Experimental study on the behaviour of a gas-solids countercurrent zig-zag contactor at trickle flow. Proc. 2 nd Eur. Powder Conf., Wiesbaden, F.R.G.

Noordergraaf, I. W., Roes, A. W. M., and van Swaaij, W. P. M., 1980b, Axial mixing and mass transfer in a zig-zag contactor. Proc. Int. Fluidization Conf., Henniker, U.S.A., pp. 341-348.

Noordergraaf, I. W., Verver, A. B., and van Swaaij, W. P. M., 1980c, Gas-Feststoff Rieselströmung und Austauschprozesse in einem Zickzack-Kontaktor. TIZFachberichte Rohstoff-Engineering 104, 534-536.

Ranz, W. E. and Marshall, W. R. J., 1952, Evaporation from drops. Chem. Engng Prog. 48, 141-146.

Reid, R. C., Prausnitz, J. M. and Sherwood, T. K., 1977, The Properties of Gases and Liquids, 3rd edn. McGraw-Hill, New York.

Roes, A. W. M., 1978, The behaviour of a gas-solid packed column at trickel flow. Thesis, Twente University of Technology, The Netherlands.

Roes, A. W. M. and van Swaaij, W. P. M., 1979a, Gas/Feststoff Rieselströmung in einer Füllkörperkolonne. Chem. Ing.Technik 51, 529.

Roes, A. W. M. and van Swaaij, W. P. M., 1979b, Hydrodynamic behaviour of a gas-solid countercurrent packed column at trickle flow. Chem. Engng J. 17, 81-89.

Roes, A. W. M. and van Swaaij, W. P. M., 1979c, Axial dispersion of gas and solid phases in a gas-solid packed column at trickle flow. Chem. Engng J. 18, 13-28.

Roes, A. W. M. and van Swaaij, W. P. M., 1979d, Mass transfer in a gas-solid packed column at trickle flow. Chem. Engng J. 18, 29-37.

Roes, A. W. M. and van Swaaij, W. P. M., 1979e, An evaluation of radial solid spread factors in a gas-solid packed column at trickle flow. Chem. Engng Sci. 34, 131-133.

Saatdjian, E. and Large, J. F., 1985, Heat transfer simulation in a raining packed bed exchanger. Chem. Engng Sci. 40, 693-697.

Supp, E. 1981, Improved methanol process. Hydrocarbon Proc. 60, 71-75.

Verver, A. B. 1984 , The catalytic oxidation of hydrogen sulphide to sulphur in a gas-solid trickle flow reactor. Thesis, Twente University of Technology, The Netherlands.

Westerterp, K. R. and Kuczynski, M., 1987, Gas-solid trickle flow hydrodynamics in a packed column. Chem. Engng Sci. 42, 1539-1551. 